INSTITUT NATIONAL DE LA STATISTIQUE ET DES ETUDES ECONOMIQUES

Série des Documents de Travail du CREST

(Centre de Recherche en Economie et Statistique)

\title{
$n^{\circ} 2009-11$
}

\section{Resale Price Maintenance and Interlocking Relationships}

P. REY ${ }^{1}$
T. VERGÉ

Les documents de travail ne reflètent pas la position de l'INSEE et n'engagent que leurs auteurs.

Working papers do not reflect the position of INSEE but only the views of the authors.

\footnotetext{
1 Toulouse School of Economics (GREMAQ, IDEI) and Institut Universitaire de France.

2 Centre de Recherche en Économie et Statistique, (CREST-LEI), Timbre J330, 15 Boulevard Gabriel Péri, 92245 Malakoff cedex, France. thibaud.verge@ensae.fr
} 


\title{
Resale Price Maintenance AND Interlocking RELATIONSHIPS ${ }^{1}$
}

\author{
Patrick Rey ${ }^{2} \quad$ Thibaud Vergé ${ }^{3}$
}

\begin{abstract}
An often expressed idea to motivate the per se illegality of RPM is that it can limit interbrand as well as intrabrand competition. This paper analyzes this argument in a context where manufacturers and retailers enter into "interlocking relationships", that is, when rival manufacturers distribute their products through the same competing retailers. It is shown that, even as part of purely bilateral vertical contracts, RPM indeed limits the exercise of both inter- and intra-brand competition and can generate industry-wide monopoly pricing. The final impact on prices depends on the extent of potential competition at either level as well as on the manufacturers' and retailers' influence in determining the terms of the contracts. Our analysis sheds a new light on ongoing legal developments and is supported by recent empirical studies.
\end{abstract}

Keywords: resale price maintenance, collusion, successive duopoly.

\section{Résumé}

Un argument fréquemment avancé pour justifier l'interdiction per se des prix de revente imposés est que ceux-ci permettent de limiter la concurrence inter-marques aussi bien qu'intramarque. Nous analysons cet argument lorsque des producteurs concurrents distribuent leurs produits par l'intermédiaire des mêmes distributeurs. Nous montrons que l'imposition du prix de revente, même dans le cadre de contrats verticaux bilatéraux, limite en effet la concurrence entre marques aussi bien qu'entre distributeurs et peut même conduire aux prix de monopole. L'impact sur les prix de détail dépend du degré de concurrence (potentielle) à chacun des niveaux, ainsi que sur la capacité de chacun des acteurs à influencer les termes des contrats. Ce papier apporte donc un éclairage sur les débats actuels. Par ailleurs, de récentes études empiriques confirment nos résultats.

Mots Clés: prix de revente imposés, collusion, duopoles successifs.

JEL Codes / Classification JEL: D4, L13, L41, L42.

\footnotetext{
${ }^{1}$ We benefited from helpful discussions with Rodolphe Dos Santos Ferreira, Bruno Jullien and Jean Tirole on an earlier draft. We are also grateful to Eric Avenel and Bill Rogerson.

${ }^{2}$ Toulouse School of Economics (GREMAQ and IDEI), 21 Allée de Brienne, 31000 Toulouse (France) [prey@cict.fr]

${ }^{3}$ CREST-LEI, Timbre J330, 15 Boulevard Gabriel Péri, 92245 Malakoff Cedex (France) [thibaud.verge@ensae.fr].
} 


\section{Introduction}

The attitude of competition authorities and courts towards vertical restraints varies significantly from one country to another or from one period to another. ${ }^{1}$ Still, until recently there was a consensus against resale price maintenance (RPM), a restraint according to which the manufacturer sets the final price that retailers charge to consumers. While competition authorities are sometimes tolerant towards some variants of RPM such as price ceilings and recommended or advertised prices, they usually treat price floors and strict RPM as per se illegal. For example, when the European Commission adopted a more open attitude towards non-price restrictions, it maintained RPM on a black list with only one other restraint. In France, price floors are per se illegal and, in Lypobar vs. La Croissanterie (1989), the Paris Court of Appeal ruled that RPM was an abuse of franchisees' economic dependency. A recent exception to this consensus concerns the U.S., where the Supreme Court overturned the long-established per se illegality of price floors, adopting instead a rule of reason approach. ${ }^{2}$

The economic analysis of vertical restraints is more ambiguous: it is not clear that RPM has a more negative impact on welfare than other vertical restraints that limit intrabrand competition. Instead, both price (e.g., RPM) and non-price restraints (e.g., exclusive territories) may have positive or negative effects on welfare, depending on the context in which they are used. ${ }^{3}$ In particular, both price and non-price vertical restraints can deal with vertical coordination problems. ${ }^{4}$ For instance, combined with non-linear wholesale tariffs, RPM or exclusive territories can equally limit free-riding problems created by strong intrabrand competition; ${ }^{5}$ several papers have moreover pointed at specific efficiency benefits of RPM. ${ }^{6}$ Vertical restraints may also affect interbrand competition. Manufacturers can for example impose restraints on retailers so as to become "less aggressive". Through strategic complementarity, this in turn induces their rivals to respond less aggressively (e.g., increase their wholesale prices) ultimately leading to higher prices

\footnotetext{
${ }^{1}$ For an overview of the legal frameworks regarding vertical restraints, see OECD (1994) or the European Commission's Green Paper on Vertical Restraints (1996). Comanor and Rey (1996) also compares the evolution of the attitudes of the U.S. competition authorities and within the European Community.

${ }^{2}$ See Leegin Creative Leather Products, Inc. v. PSKS, Inc., 127 S.Ct 2705 (2007).

${ }^{3}$ See Motta (2004, chapter 6) or Rey and Vergé (2008) for recent surveys of that literature.

${ }^{4}$ Rey and Tirole (1986) offers an overview of the relative merits of price and non-price restrictions in improving vertical coordination.

${ }^{5}$ Note however, that depending on the structure of consumer demand, such restraints may harm or enhance economic welfare. See (among others) Spence (1975), Comanor (1985), Caillaud and Rey (1987), or more recently Schulz (2007).

${ }^{6}$ For example, Marvel and McCafferty (1984) stress that RPM can help manufacturers to purchase certification from reputable dealers. Deneckere, Marvel and Peck (1996, 1997) and Wang (2004) show that RPM can encourage retailers to hold inventories in the presence of demand uncertainty, while Chen (1999) shows that RPM may help controlling retail price discrimination.
} 
and profits. ${ }^{7}$ To achieve this, manufacturers must however give retailers some freedom in their pricing policies. Granting exclusive territories (thus eliminating intrabrand competition) would for example serve this purpose and have an adverse effect on consumer surplus and economic welfare, whereas RPM would have no impact since it eliminates the retailers' freedom to choose their retail prices. Overall, a comparison of the welfare effects of exclusive territories, RPM and exclusive dealing does not clearly justify a more lenient attitude towards non-price restrictions. ${ }^{8}$

To justify their negative attitude towards price restrictions, courts have however put forward an industry-cartellization argument. For example, in Business Electronics, the Supreme Court justified the per se illegality of RPM by claiming that "there was support for the proposition that vertical price restraints reduce inter-brand price competition because they facilitate cartelizing." This type of argument has also been informally used by Telser (1960) and Mathewson and Winter (1998). It was formalized recently by Jullien and Rey (2007) who stress that, by making retail prices less responsive to local shocks on retail cost or demand, RPM yields more uniform prices that facilitate tacit collusion - by making deviations easier to detect.

This paper analyzes this "facilitating practice" argument from a different perspective. We show that, even in the absence of repeated interactions, RPM can eliminate any effective competition when manufacturers and retailers engage in "interlocking relationships", that is, when manufacturers distribute their goods through the same competing distributors. The intuition is relatively simple. In the case of a (local) retail monopoly we know that, through "common agency", competing manufacturers can avoid interbrand competition, e.g., by selling at cost in exchange for a fixed fee: since manufacturers internalize through fixed fees the impact of prices on the retailer's profit, eliminating the upstream margin on one brand transforms a rival manufacturer into a residual claimant on the sales of both brands. As a result, the rival manufacturer has an incentive to maintain retail prices at the monopoly level, which it can achieve precisely by supplying at cost. Simple two-part tariffs therefore suffice to maintain monopoly prices and profits. ${ }^{9}$ This is no longer the case when there is competition not only between brands, but also between retailers, since intrabrand competition reduces retail margins. Manufacturers then face conflicting incentives: keeping low upstream margins to avoid interbrand competition, and increasing wholesale prices to maintain high retail prices despite intrabrand competition. As we will see, two-part tariffs no longer suffice to maintain industry profits, and retail prices are instead set below their monopoly level. Manufacturers can however

\footnotetext{
${ }^{7}$ See for example Rey and Stiglitz (1988, 1995), Bonanno and Vickers (1988) and Gal-Or (1991). Caillaud and Rey (1995) offer a survey of this literature on strategic delegation.

${ }^{8}$ See Caballero-Sanz and Rey (1996).

${ }^{9}$ See Bernheim and Whinston $(1985,1998)$ and O'Brien and Shaffer (1997).
} 
use RPM to eliminate intrabrand competition and restore monopoly prices and profits. In particular, selling at cost (for a fee) still makes rivals internalize (through their own fees) the full impact of their prices on the sales of a manufacturer's brand. At the same time, a manufacturer can now maintain high retail prices for its brand through RPM. Combining two-part tariffs with RPM thus provides a mechanism through which manufacturers can give each other incentives to maintain high retail prices and profits. Both interbrand and intrabrand competition are then totally eliminated, even though contracts (including retail prices) are negotiated on a purely bilateral basis. In the absence of any retail bottleneck (e.g., when there are potential competitors for each retail location), manufacturers clearly benefit from this, since they can appropriate most of the profits that their products generate. When instead retailers have market power, manufacturers need to leave them some rents, thus reducing their incentives to deal with both retailers and to maintain monopoly prices. As a result, all channels may not be active and manufacturers may moreover favor lower prices, in order to keep a larger share of an admittedly smaller pie, whereas retailers would instead favor higher retail prices.

Note that the mechanism identified here could not be replicated through other standard means of reducing intrabrand competition, e.g., by granting an exclusive right over some territory. In particular, RPM allows manufacturers to avoid interbrand competition even when, due to retailers' differentiation strategies, meeting consumer demand makes it undesirable to grant exclusive territories and exclude some of the established retailers.

This paper is closely related to that of Dobson and Waterson (2007), who study a similar bilateral duopoly with interlocking relationships. Assuming that manufacturers use (inefficient) linear wholesale prices, they show that the welfare effects of RPM depend on the relative degree of upstream and downstream differentiation as well as on retailers' and manufacturers' bargaining powers; RPM can be socially preferable when retailers are in a weak bargaining position, because the double-marginalization problems generated by the use of linear wholesale prices is more severe in such circumstances. ${ }^{10}$ In order to eliminate double marginalization problems and focus instead on the impact of RPM on interbrand and intrabrand competition, we do not restrict attention to linear tariffs but allow for bilaterally efficient (two-part) wholesale tariffs. ${ }^{11}$

Our analysis sheds an interesting light on recent legal developments. While the US Supreme Court recently overturned the per illegality of RPM, in France, RPM, together

\footnotetext{
${ }^{10}$ In a similar context, Allain and Chambolle (2007) moreover show that non-discriminatory price floors can help maintain high retail prices even when manufacturers can grant secret rebates.

${ }^{11}$ Another difference concerns the equilibrium concept. To reflect different bargaining powers, Dobson and Waterson (2007) assume that wholesale prices are determined by simultaneous pairwise bargaining. This supposes that a manufacturer has two independent divisions, each of them negotiating with one retailer not taking into account the impact of its own negotiation on the other division.
} 
with non-linear wholesale tariffs, has instead raised concerns in markets where multiple producers distribute their goods through the same retailers. For example, in December 2005, the Conseil de la Concurrence (one of the two French competition authorities) condemned brown goods manufacturers Panasonic, Philips and Sony for "vertical collusion" with their wholesalers and retailers. The Conseil de la Concurrence concluded that there was evidence that these manufacturers were actively monitoring retailers in order to ensure that they were actually following their recommended retail prices (this was especially the case for new product lines) and were pushing wholesalers to refuse to supply price-cutting retailers. ${ }^{12}$ For the same practices, the major perfume manufacturers (L'Oréal, Chanel, Guerlain, Dior, ...) and retailers (Nocibé, Marionnaud, Séphora) were fined a total of 44 million euros, and toy manufacturers (Chicco, Lego, ...) and retailers (Carrefour, JouéClub, ...) were fined a total of 37 million euros. ${ }^{13}$

Our analysis is also relevant for the ongoing reform of the French competition rules banning below-cost pricing. In order to simplify billing methods and enhance transparency, the 1996 Galland Act defined the relevant cost threshold as being the invoice-price paid by the retailer at the time of delivery. This opened the possibility of using below-cost pricing rules to impose de facto retail price floors, by artificially inflating the invoice prices, together with end-of-year and other hidden rebates so as to maintain similar "net" wholesale prices. This reform has been heavily criticized for contributing to the important price increases that took place after 1997, especially for the major national brands present in all supermarket chains. As we will see, our analytical framework supports this claim and has moreover been validated by recent empirical studies. ${ }^{14}$

This paper is organized as follows. Section 2 presents our framework, where two rival manufacturers distribute their goods through two competing retailers; this framework allows for interlocking relationships (or "double common agency"): each manufacturer can deal with both retailers, and conversely each retailer can carry both brands. Section 3 provides a preliminary analysis of "intrinsic" double common agency situations: while retail prices are lower than the monopoly price in the absence of RPM, with RPM there exist many equilibria, including one in which retail prices and manufacturers' profits are at the monopoly level. We then endogenize the market structure. Section 4 studies situations with potential competition downstream for each retail location. Both brands are then always present at both retail locations and the previous analysis applies; in

\footnotetext{
${ }^{12}$ These three manufacturers were respectively fined 2.4, 16 and 16 million euros. Panasonic was later cleared by the Court of Appeal. Other major manufacturers present on the French market were also investigated, but the Conseil de la Concurrence did not find enough evidence to convict them. See Conseil de la Concurrence, decision 05-D-66, December 2005.

${ }^{13}$ See Conseil de la Concurrence, decisions 06-D-04 (March 2006, Perfumes) and 07-D-50 (December 2007, Toys).

${ }^{14}$ See Biscourp, Boutin and Vergé (2008) and Bonnet and Dubois (2007 and 2008).
} 
particular, when RPM is allowed, there always exists an equilibrium with monopoly prices and profits. Section 5 turns to the case of retail bottlenecks, where manufacturers cannot bypass established retailers. Manufacturers must then leave a rent to retailers to induce them to sell their products; relatedly, they can attempt to eliminate their competitor by inducing the retailers to reject their rival's offer. As a result, it can be the case that no equilibrium exists where both retailers carry both brands, even though there is demand for each brand at each store. In addition, while there may exist a continuum of equilibria with RPM, equilibria with higher retail prices now involve larger rents for the retailers and lower profits for the manufacturer - implying that manufacturers favor equilibria with rather "competitive" prices. Section 6 discusses the empirical validation as well as the policy implications of our analysis.

\section{The basic framework}

There are two manufacturers, $A$ and $B$, each producing its own brand, and two differentiated retailers, 1 and 2 - retailers may for example differ in their location or the services they provide to consumers. If both retailers carry both brands, consumers choose among four imperfectly substitutable "products", each manufacturer producing two of them $(\{A 1, A 2\}$ and $\{B 1, B 2\}$, respectively) and each retailer distributing two of them $(\{A 1, B 1\}$ and $\{A 2, B 2\}$, respectively).

In order to avoid that one firm - manufacturer or retailer - plays a particular role, we suppose that demand functions are symmetric; for any price vector $\mathbf{p}=\left(p_{A 1}, p_{B 1}, p_{A 2}, p_{B 2}\right)$, any $i \neq h \in\{A, B\}$ and any $j \neq k \in\{1,2\}$, the demand for brand $i$ at store $j$ is $D_{i j}(\mathbf{p}) \equiv$ $D\left(p_{i j}, p_{h j}, p_{i k}, p_{h k}\right)$, where the function $D($.$) is continuously differentiable. In what fol-$ lows, we will drop the arguments in $D_{i j}$ when there is no risk of confusion, and systematically use subscripts $i$ and $h$ for the two manufacturers, and $j$ and $k$ for the two retailers. The products being (imperfect) substitutes, we suppose that the demand for one product decreases with the price of that product and increases with the other prices: ${ }^{15} \partial_{1} D<0$ and $\partial_{n} D>0{ }^{16}$ for $n=2,3,4$. Furthermore, we suppose that direct effects dominate, so that demand decreases if all prices increase: $\sum_{n=1}^{4} \partial_{n} D<0$. We also assume that both production and distribution unit costs are symmetric and constant, and denote them respectively by $c$ and $\gamma \cdot{ }^{17}$ The industry profit is thus equal to

\footnotetext{
${ }^{15}$ We denote by $\partial_{n} f$ the partial derivative of $f$ with respect to its $n^{\text {th }}$ argument.

${ }^{16}$ This assumption seems reasonable but is not always maintained. For example, Dobson and Waterson (2007) consider a linear model where the price of one product decreases when the quantity of any product increases. Their specific assumptions however imply that the demand for one brand in one store decreases when the price of the competing brand increases in the competing store $\left(\partial_{4} D<0\right)$.

${ }^{17} \mathrm{We}$ assume constant returns to scale only for expositional simplicity. The analysis would remain unchanged when fixed costs are for example taken into consideration; more generally, it should become
} 
$\sum_{i=A, B} \sum_{j=1,2}\left(p_{i j}-c-\gamma\right) D_{i j}(\mathbf{p})$. Throughout the paper, we assume that this industry profit is concave in $\mathbf{p}$, maximal for symmetric prices, $\mathbf{p}^{M}=\left(p^{M}, p^{M}, p^{M}, p^{M}\right)$ and denote by $\Pi^{M}$ this maximum (from now on, we will refer to $\Pi^{M}$ as the monopoly profit).

To fix ideas, we assume throughout the paper that the manufacturers have all the bargaining power. We thus consider a two-stage game where at stage 1, manufacturers offer contracts to the retailers, and, at stage 2 , retailers compete on the downstream market.

\section{Preliminary analysis: intrinsic double common agency}

We assume in this section that the market structure is necessarily that of a double common agency, by supposing that the market "breaks down" whenever a retailer refuses to carry a brand. This assumption is admittedly ad-hoc and is only introduced here to present the main intuition in a simple way; it is relaxed in the following sections. ${ }^{18}$ As we will see, this preliminary analysis provides an adequate characterization of equilibrium prices and profits when potential competition from alternative distribution channels prevent manufacturers from excluding their rivals and retailers from obtaining any rents (section 4). However, the existence of double common agency equilibria and the distribution of rents become relevant issues when retailers have market power (section 5).

We thus consider in this section the following simple two-stage game $G$ :

\section{- Stage 1: Upstream competition}

$(\mathbf{1}-\mathbf{A})$ Each manufacturer $(i=A, B)$ proposes a contract to each retailer $(j=1,2)$. Contract offers are simultaneous and publicly observable, ${ }^{19}$ and consist of a wholesale two-part tariff $\left(w_{i j}, F_{i j}\right)$ and, if allowed, of a retail price $p_{i j}{ }^{20}$ Retailers then simultaneously decide whether to accept or reject the offers, and acceptance decisions are public.

$(\mathbf{1}-\mathbf{B})$ If all offers are accepted, the game proceeds to stage 2; otherwise, the game ends with all firms earning zero profits.

\section{- Stage 2: Downstream competition}

clear to the reader that the thrust of the argument does not rely on a specific formulation of upstream and downstream costs.

${ }^{18}$ This preliminary analysis is similar in spirit to the "intrinsic common agency" game that Bernheim and Whinston (1985) use to present their main insight.

${ }^{19}$ The observability assumption avoids technicalities such as the definition of reasonable conjectures in the event of unexpected offers, and equilibrium existence problems; see Rey and Vergé (2004a).

${ }^{20} \mathrm{~A}$ manufacturer can choose to offer no contract by "proposing" prohibitively high wholesale prices or franchise fees. 
Retailers simultaneously set retail prices (as imposed by the manufacturer under RPM) for all the brands they have accepted to carry, demands are satisfied and payments made according to the contracts.

The simplifying "market break-down" assumption $(1-B)$ ensures that manufacturers offer contracts that are acceptable by both retailers, and that retailers never obtain more than their reservation utility, which we normalize to zero.

\subsection{Two-part tariffs}

Let us first suppose that contracts can only consist of two-part tariffs. In the second stage, each retailer $j=1,2$ sets its prices $p_{A j}$ and $p_{B j}$ so as to maximize its profit,

$$
\pi_{j}=\sum_{i=A, B}\left(p_{i j}-w_{i j}-\gamma\right) D_{i j}-F_{i j}
$$

We assume that, for any vector of wholesale prices $\mathbf{w}=\left(w_{A 1}, w_{B 1}, w_{A 2}, w_{B 2}\right)$, there exists a unique retail price equilibrium $\mathbf{p}^{r}(\mathbf{w})=\left(p_{A 1}^{r}(\mathbf{w}), p_{B 1}^{r}(\mathbf{w}), p_{A 2}^{r}(\mathbf{w}), p_{B 2}^{r}(\mathbf{w})\right)$, and denote by $D_{i j}^{r}(\mathbf{w})=D_{i j}\left(\mathbf{p}^{r}(\mathbf{w})\right)$ the resulting demand for each product.

In the first stage each manufacturer $i=A, B$ chooses wholesale prices $w_{i 1}$ and $w_{i 2}$, and franchise fees $F_{i 1}$ and $F_{i 2}$, so as to maximize its profit subject to retailers' participation constraints. Since retailers can only accept both offers or earn zero profit, manufacturer $i$ seeks to solve:

$$
\begin{gathered}
\max _{\left(w_{i j}, F_{i j}\right)_{j=1,2}} \sum_{j=1,2}\left(w_{i j}-c\right) D_{i j}^{r}(\mathbf{w})+F_{i j}, \\
\text { s.t. } \quad \sum_{h=A, B}\left(p_{h j}^{r}(\mathbf{w})-w_{h j}-\gamma\right) D_{h j}^{r}(\mathbf{w})-F_{h j} \geq 0 \text { for } j=1,2 .
\end{gathered}
$$

The participation constraints are clearly binding and the program is thus equivalent to:

$$
\max _{w_{i 1}, w_{i 2}} \Pi_{i}^{r}(\mathbf{w}) \equiv \sum_{j=1,2}\left(\left(p_{i j}^{r}(\mathbf{w})-c-\gamma\right) D_{i j}^{r}(\mathbf{w})+\left(p_{h j}^{r}(\mathbf{w})-w_{h j}-\gamma\right) D_{h j}^{r}(\mathbf{w})\right) .
$$

In other words, through the franchise fees each manufacturer $i=A, B$ internalizes the impact of its pricing decisions on (i) the entire margins $\left(p_{i j}-c-\gamma\right)$ on its own product (for $j=1,2)$ and (ii) the retail margins $\left(p_{h j}-w_{h j}-\gamma\right)$ on the rival product; it therefore ignores the rival's upstream margins $\left(w_{h j}-c\right)$. As a result, (symmetric) equilibrium prices are somewhat competitive (i.e., below the monopoly level) whenever the retail equilibrium satisfies weak regularity conditions.

\section{Assumption 1}

i) For symmetric wholesale prices $\left(w_{i 1}=w_{i 2}=w_{i}\right.$ for $\left.i=A, B\right)$, equilibrium retail prices are symmetric: $p_{i 1}^{r}=p_{i 2}^{r} \equiv \widetilde{p}\left(w_{i}, w_{h}\right)$ for $i \neq h=A, B$, leading to symmetric quantities $D_{i 1}^{r}=D_{i 2}^{r} \equiv \widetilde{D}\left(w_{i}, w_{h}\right)$; moreover: 
ii) an increase in all wholesale prices increases retail prices: $\partial_{1} \widetilde{p}+\partial_{2} \widetilde{p}>0$;

iii) an increase in one manufacturer's wholesale prices decreases the demand for that manufacturer and increases the demand for its rival: $\partial_{1} \widetilde{D}<0<\partial_{2} \widetilde{D}$.

These conditions are for example satisfied when retail prices are strategic complements and direct effects dominate indirect ones. ${ }^{21}$ In particular, they are satisfied in the linear demand case analyzed in section 5 .

Proposition 1 Without RPM, under Assumption 1, any symmetric equilibrium of the form $w_{i j}=w^{e}$ and $p_{i j}=p^{e}$ satisfies $c<w^{e}<p^{e}<p^{M}$.

\section{Proof. See Appendix A.}

If there were a monopoly at either level, (public) two-part tariffs would instead lead to retail prices equal to monopoly prices. For example, if a single manufacturer were selling through competing retailers, it would set wholesale prices high enough to induce retail prices at the monopoly level - and would then recover retail margins through franchise fees. Likewise, if a single retailer were acting as a common agent for several manufacturers, as in Bernheim and Whinston (1985), manufacturers would sell at marginal cost, thereby inducing the retailer to adopt monopoly prices, and would again recover profits through franchise fees.

Here, in contrast, the existence of competition at both the upstream and downstream levels maintains retail prices below the monopoly level. This is because, as noted above, manufacturers only take into account the retail margin on rival products, and thus fail to account that a reduction in their own prices hurt their rival's upstream profits. If, for example, retailers are pure Bertrand competitors (that is, assuming away any downstream differentiation), they are both active only if wholesale prices are symmetric $\left(w_{i j}=w_{i}\right)$, in which case retail prices simply reflect wholesale prices $\left(p_{i j}=w_{i}\right)$ and franchise fees are zero, so that manufacturer $i$ 's profit reduces to $\Pi_{i}^{r}(\mathbf{w}) \equiv\left(w_{i}-c-\gamma\right) \hat{D}_{i}\left(w_{A}, w_{B}\right)$, where $\hat{D}_{i}\left(p_{A}, p_{B}\right)$ represents the demand for product $i=A, B$ when the price of product $A$ (respectively $B$ ) is $p_{A}$ (respectively $p_{B}$ ). The situation is then formally the same as if the two manufacturers were directly competing against each other.

\subsection{Resale price maintenance}

Suppose now that manufacturers can resort to RPM. Imposing retail prices is then always a dominant strategy for the manufacturers: whatever the strategy adopted by its rival,

\footnotetext{
${ }^{21}$ For example, $\partial_{1} \widetilde{p} \geq \partial_{2} \widetilde{p}>0$ implies $\partial_{1} \widetilde{D}<0$ and $\partial_{1} \widetilde{p}>\left(-\lambda_{M} / \hat{\lambda}_{M}\right) \partial_{2} \widetilde{p}$, where $\lambda_{M}$ (respectively, $\hat{\lambda}_{M}$ ) denotes the impact on demand for the "product" ij of a uniform increase in manufacturer $i$ 's (respectively, $h$ 's) prices, implies $\partial_{2} \widetilde{D}>0$.
} 
a manufacturer can always replicate, with RPM, the retail prices that would emerge and the profits it would earn without RPM.

Under RPM, the last stage of the game is straightforward. In the first stage, if manufacturer $h$ imposes retail prices $\left(p_{h 1}, p_{h 2}\right)$, manufacturer $i$ will choose wholesale prices $w_{i 1}$ and $w_{i 2}$, retail prices $p_{i 1}$ and $p_{i 2}$, and franchises $F_{i 1}$ and $F_{i 2}$ so as maximize its profit, given the retailers' participation constraints:

$$
\begin{array}{cc} 
& \max _{\left(w_{i j}, p_{i j}, F_{i j}\right)_{j=1,2}} \sum_{j=1,2}\left(w_{i j}-c\right) D_{i j}(\mathbf{p})+F_{i j}, \\
\text { s.t. } \quad & \sum_{h=A, B}\left(p_{h j}-w_{h j}-\gamma\right) D_{h j}(\mathbf{p})-F_{h j} \geq 0 \text { for } j=1,2 .
\end{array}
$$

or, since the participation constraints are clearly binding:

$$
\max _{\left(p_{i 1}, p_{i 2}\right)} \Pi\left(\mathbf{p}, w_{h 1}, w_{h 2}\right) \equiv \sum_{j=1,2}\left(p_{i j}-c-\gamma\right) D_{i j}(\mathbf{p})+\left(p_{h j}-w_{h j}-\gamma\right) D_{h j}(\mathbf{p})
$$

As before, each manufacturer fully internalizes (through the franchise fees that it can extract from the retailers) the entire margins on its product, but internalizes only the retail margins on the rival's product. But now, the manufacturer's wholesale prices no longer affect its profit (previously, these wholesale prices had an indirect effect through retailers' prices, which are now directly controlled by the manufacturer); however, as the program (1) makes clear, these wholesale prices affect the rival's profit and thus its equilibrium behavior. As a result, there can exist a continuum of equilibria - one for every profile of wholesale prices $w=\left(w_{A 1}, w_{B 1}, w_{A 2}, w_{B 2}\right)$.

If for example manufacturer $h$ sells at cost $\left(w_{h 1}=w_{h 2}=c\right)$, program $(1)$ becomes:

$$
\max _{p_{i 1}, p_{i 2}} \sum_{j=1,2}\left(p_{i j}-c-\gamma\right) D_{i j}(\mathbf{p})+\left(p_{h j}-c-\gamma\right) D_{h j}(\mathbf{p}) .
$$

Manufacturer $i$ then fully internalizes the impact of its retail prices on aggregate profits, and thus sets its prices at the monopoly level if manufacturer $h$ does also so; there thus exists an equilibrium in which both manufacturers set wholesale prices to $c$ and retail prices to the monopoly level, and share monopoly profits. RPM can thus prevent the exercise of interbrand as well as intrabrand competition. ${ }^{22}$

If instead manufacturers adopt wholesale prices above cost, they tend to choose more aggressive retail prices for their own brand, since they do not take into account the upstream margins on the rival brand. As a result, one expects an inverse relation between wholesale and retail prices. The next proposition confirms this intuition under the following regularity conditions:

\footnotetext{
${ }^{22}$ The argument still applies when marginal costs are not constant, interpreting $c$ as the marginal cost for monopolistic production levels.
} 
Assumption 2 There exists a range $W \subset \mathbb{R}$ such that, for $h=A, B$ and any $w_{h 1}=$ $w_{h 2}=w_{h} \in W:$

i) For any $i \neq h \in\{A, B\}$ and $p_{h 1}=p_{h 2}=p_{h}$, the revenue function $\Pi$ is single-peaked in $\left(p_{i 1}, p_{i 2}\right)$ and maximal for symmetric prices, $\hat{p}_{i 1}=\hat{p}_{i 2}=\hat{p}\left(p_{h}, w_{h}\right)$;

ii) $\hat{p}(.,$.$) satisfies 0<\partial_{1} \hat{p}<1$ and the function $p \rightarrow \hat{p}\left(p, w_{h}\right)$ has a unique fixed point.

This assumption first states that retail price responses are well defined and preserve symmetry; in addition, for any symmetric profile of wholesale prices, there exists a unique, stable, "retail equilibrium" (looking at a reduced game where manufacturers would simply choose retail prices, taking wholesale prices as given). Assumption 2 holds for example in the linear case studied in section 5 . We have:

Proposition 2 If RPM is allowed then:

i) There always exists a symmetric subgame perfect equilibrium in which wholesale prices are equal to cost $\left(w^{*}=c\right)$, retail prices are at the monopoly level $\left(p^{*}=p^{M}\right)$, retailers earn zero profit and manufacturers share equally the monopoly profit.

ii) Under Assumption 2, there moreover exists a decreasing function $p^{*}$ (.) such that, for any $w^{*} \in W$, there exists a symmetric subgame perfect equilibrium in which wholesale prices are equal to $w^{*}$, retail prices are equal to $p^{*}\left(w^{*}\right)$, and retailers earn zero profit.

\section{Proof. See Appendix B.}

There is thus a continuum of symmetric equilibria and, within this set of equilibria, retail prices are inversely related to wholesale prices. Retail prices are at the monopoly level when wholesale prices are equal to cost - in this equilibrium, manufacturers thus "eliminate" any competition and achieve monopoly profits - while wholesale mark-ups yield lower retail prices. ${ }^{23}$ In essence, with RPM, the situation is one where manufacturers deal with two, non-competing, common agents. Consider for example the polar case where retailers are pure Bertrand competitors (no downstream differentiation). With RPM the manufacturers eliminate retail competition and de facto allocate half of the demand for their products to each retailer; the monopolistic equilibrium then simply mimics the Bernheim and Whinston (1985) common agency equilibrium (without RPM) within each half-market. The above analysis generalizes this insight to the case where retailers are differentiated.

\section{- Bilateral bargaining power}

\footnotetext{
${ }^{23}$ Conversely, negative upstream margins would sustain retail prices above the monopoly level. The range of equilibrium prices depends on the domain of validity of Assumption 2. For example, for the linear demand used in section 5 , any retail price from $c+\gamma$ up to the price for which quantities are 0 can be sustained.
} 
While we have assumed here that manufacturers have all the bargaining power and make take-it or leave-it offers to retailers, the analysis is similar if retailers are the ones that propose the contracts in stage $1-A$. With RPM, there again exists an equilibrium in which prices are at the monopoly level - although now the retailers rather than the manufacturers get all the profits. To achieve this, however, instead of squeezing the upstream margin $\left(w^{*}=c\right)$, the retailers need to squeeze the downstream margin $\left(w^{*}=p^{M}-\gamma\right)$, so as to allow each of them to internalize the whole margin on the sales of the other retailer franchise fees being used to extract the manufacturers' expected revenues (slotting fees i.e., negative franchise fees - are needed in this setting to transfer profits downstream).

\subsection{Effort and equilibrium selection}

Resorting to RPM generates a coordination problem that does not arise in the context of a single common agent: ${ }^{24}$ there exist here (infinitely) many other equilibria, including very competitive ones. ${ }^{25}$ While there always exists an equilibrium yielding monopoly profits (even in the absence of Assumption 2), the manufacturers may end up being locked into a "bad" equilibrium.

This multiplicity comes from the fact that manufacturers have more control variables than "needed." Retail prices allow a manufacturer to monitor the joint profits earned together with the retailers, while both franchise fees and wholesale prices can be used to recover retailers' profits. The multiplicity of equilibria then derives from the fact that a manufacturer is indifferent with respect to the level of its wholesale prices, which however drive its rival's decisions. It is thus difficult to draw policy implications, since some equilibria are better and others worse than the equilibrium that would emerge in the absence of RPM.

One way to circumvent this issue is to introduce a (non contractible) retail effort which affects the demand and is chosen by the retailers at the same time as they set prices. To fix ideas, suppose that, at the downstream competition stage, each retailer can increase the demand for a brand it distributes by exerting some costly effort. In contrast with the previous situation, manufacturers are no longer indifferent as to the choice of their wholesale prices, since they affect retail efforts. There are no longer more control

\footnotetext{
${ }^{24}$ In single common agency situations, several equilibria exist but they only differ on how the manufacturers share the monopoly profit. In particular, there exists a unique symmetric equilibrium in two-part (or non-linear) tariffs, which yields the monopoly outcome. However, introducing $R P M$ would again generate a multiplicity of (symmetric) equilibria, since as above each manufacturer would respond to its rival's wholesale price and be indifferent as to its own wholesale price. Introducing $R P M$ in that case is not helpful and even possibly harmful for the manufacturers.

${ }^{25}$ While the previous proposition shows that there exists a continuum of symmetric equilibria, the same logic allows as well to construct equilibria around asymmetric wholesale prices.
} 
variables than targets, as a consequence, the multiplicity disappears. To provide adequate incentives, manufacturers must make retailers residual claimants for their efforts, which requires wholesale prices equal to marginal cost. As a result, equilibrium wholesale prices are always equal to the marginal cost, and the only equilibria that are robust to the introduction of retail efforts therefore lead to the monopoly outcome. ${ }^{26}$

\section{Competitive retailers}

The previous "intrinsic double common agency" game allowed us to describe the key intuition in a simple way but relies on an ad-hoc "market break-down" assumption. While this assumption is, as such, unrealistic, it captures however essential aspects of potential retail competition. Indeed, if manufacturers can easily find equally efficient alternative channels for each retail location then, as in the previous section, the following two features are likely to hold:

- retailers have no bargaining power, so that manufacturers extract all profits;

- manufacturers cannot exclude their rivals from any retail location.

The analysis of the precedent section is then likely to prevail: manufacturers are deemed to "accommodate" each other and their best strategy is to maintain monopoly prices and share the monopoly profits, which they can indeed achieve by adopting common retailers (rather than marketing their products themselves or through different retailers) and eliminating intrabrand competition between these common retailers through RPM.

To capture such absence of retail bottleneck in a simple way, we now interpret $D_{i j}$ as the demand for brand $i=A, B$ at retail location $j=1,2$; and assume that, for each retail location, each manufacturer has access to at least one potential alternative, equally efficient retailer. Manufacturers can thus either distribute their products through the established retailers (who can carry both brands) or bypass them and use instead alternative (exclusive) retailers. We denote by $1_{A}, 1_{B}, 2_{A}$ and $2_{B}$ the alternative retailers and assume that they face the same retail cost $\gamma$ as the established retailers. In order to stick as much as possible to the above analysis, we assume that manufacturers first try to deal with established retailers and therefore adapt the competitive game $G$ by modifying the second step of the upstream competition stage as follows:

$(\mathbf{1}-\mathbf{B})^{\prime}$ Whenever a manufacturer has an offer rejected by a retailer, it proposes a contract to its relevant alternative retailer. All offers to alternative retailers are again simultaneous and public, as well as their acceptance decisions.

\footnotetext{
${ }^{26}$ The complete analysis is available in an earlier version of this paper; see Rey and Vergé (2004b).
} 
The first step of the upstream competition stage thus still allows the manufacturers to adopt a common retailer at each location, while the second step now captures the absence of retail bottleneck: a manufacturer whose offer is rejected in step $1-A$ can still market its product through the alternative retailer in step $(1-B)^{\prime}$. This, in effect, prevents manufacturers from trying to foreclose their rivals' access to consumers; as we will see, it also encourages retailers to accept any offer that gives them non-negative profits. More generally, alternative retailers need not be exclusive and might well deal with both manufacturers; conversely, manufacturers could also make offers to alternative retailers at stage one as well (see the discussion below). This would not affect the essence of the analysis but would however complicate its exposition, by increasing the number of cases to be considered.

In the absence of RPM, a retailer that chooses to carry a single brand - brand $A$, say - is likely to face tougher competition. Indeed, when turning to its alternative retailer, manufacturer $B$ does not internalize anymore the impact of its price on the margins of manufacturer $A$ and of the other retailer (since its fee has already been negotiated). This makes manufacturer $B$ more aggressive (through a lower wholesale price for the alternative retailer), which tends to result in lower retail prices and downstream profits. As a result, refusing the offer of one manufacturer in step $1-A$ is therefore likely to make the other manufacturer's offer less attractive and, as in the previous section the retailers' relevant choices are then to accept both offers or none. ${ }^{27}$ The proof of proposition 1 then carries over, ensuring that in equilibrium, retailers obtain no rent and prices are somewhat competitive, not only when the manufacturers rely on different retailers in a given local market, but also when they rely on common retailers.

When RPM is allowed, the preliminary analysis outlines a candidate equilibrium where manufacturers share the monopoly profit: in this candidate equilibrium, manufacturers adopt the established retailers as common agents, supply at cost, impose monopolistic retail prices and extract all profits through franchise fees. By construction, no deviation is profitable for a manufacturer if retailers keep accepting the rival's offers. ${ }^{28}$ However, by deviating and opting for a more aggressive behavior, a manufacturer can now discourage a

\footnotetext{
${ }^{27}$ Providing general conditions under which mono-branding results in lower retail prices and profits proves cumbersome, but it holds for example in the linear model that we consider in the next section. It holds as well if the "alternative retailer" consists of direct distribution: in that case, the wholesale price goes down to cost and, failing to internalize the impact of its price on the other brand, a mono-brand retailer moreover sets a lower margin than a multi-brand retailer would do. Retail prices and downstream profits are then lower whenever retail prices are strategic complements and the retail equilibrium is stable.

${ }^{28}$ Since each manufacturer gets half the monopoly profit when its offers are accepted by the two retailers, and retailers will not accept offers that yield negative profits.
} 
retailer from carrying the rival brand. ${ }^{29}$ In essence, such moves allow the deviating manufacturer to act as a Stackelberg leader: imposing a price below the monopoly level forces the rival to deal with the alternative retailers and therefore to set retail prices that "best respond" to the deviating manufacturer's prices. Such deviations are however unattractive when, as one may expect, Stackelberg profits - which involve some competition - are lower than monopoly profits.

The following proposition confirms this intuition and shows that, under mild conditions, the previous characterization of double common agency equilibrium outcomes still applies in the absence of the "market break-down assumption. To introduce the relevant conditions, we need to consider two hypothetical scenarios of Stackelberg competition: in the first scenario, the leader (respectively, the follower) produces at cost $c+\gamma$ the "products" $A 1$ and $A 2$ (respectively, $B 1$ and $B 2$ ); in the second scenario, the leader produces three products, $A 1, A 2$ and $B 1$, while the follower produces $B 2$. The first scenario is thus a mere extension of the standard Stackelberg price competition to a symmetric duopoly in which each firm produces and sells two products, while the second scenario involves asymmetric firms.

Assumption 3 In the two Stackelberg scenarios just described, the leader's average profit is, per product, lower than the monopoly profit.

In the first scenario, the requirement is satisfied whenever prices are strategic complements: Gal-Or (1985) shows indeed that the leader's profit is then lower than the follower's profit, ${ }^{30}$ and since the industry-wide profit cannot exceed the monopoly level, the leader's profit is thus less than half the monopoly profit. Amir and Grilo (1994) note that the comparison between the leader's and the follower's profits is more ambiguous when they are in an asymmetric position, as in the second scenario; however, there is still some competition between the two firms, and since the follower sells one product only, it is likely to be even more aggressive, so that the above requirement sounds again quite reasonable. Assumption 3 is for example always satisfied in the linear case analyzed in section 5 as well as when prices are strategic complements and there is strong intrabrand or interbrand competition. ${ }^{31}$

\footnotetext{
${ }^{29}$ Retailers will refuse the manufacturer's offer, which involves a franchise fee equal to the monopoly profit (per product), whenever they expect rival prices below the monopoly level.

${ }^{30}$ When prices are strategic complements, the leader $(L)$ is willing to increase its prices in order to encourage the follower $(F)$ to (partially) follow-up and, as a result, in equilibrium $L$ 's prices are higher than F's ones; thus, $F$ "best responds" to $L$ 's comparatively higher prices, while $L$ does not even best respond to $F$ 's lower prices.

${ }^{31}$ The second, asymmetric Stackelberg scenario boils down to a symmetric Stackelberg duopoly when there is strong intrabrand and/or interbrand competition. Suppose for example that retailers are perfect substitutes (no downstream differentiation); that is, there is a demand $D_{i}\left(p_{A}, p_{B}\right)$ for brand $i=A, B$ and
} 
Assumption 4 The revenue function $\pi(p)=(p-c-\gamma) D\left(p, p^{M}, p^{M}, p^{M}\right)$ is maximal for a price lower than $p^{M} .^{32}$

Proposition 3 When RPM is allowed, under Assumptions 3 and 4, there exists a subgame perfect equilibrium where manufacturers adopt common retailers (double common agency) and set wholesale prices to marginal cost $\left(w^{c}=c\right)$ and retail prices to the monopoly level $\left(p^{c}=p^{M}\right)$, and achieve monopoly profits (that is, retail profits are zero).

\section{Proof. See Appendix C.}

The intuition underlying this result is straightforward. It is impossible for a manufacturer to exclude its competitor from any location, since the rival always finds it profitable to deal with its alternative retailer for that location. But then, the best way to "accommodate" the rival manufacturer is by adopting RPM and sharing retailers. As noted in the previous section, RPM eliminates competition between the common agents, and common agency "eliminates" competition between the manufacturers.

Two-part tariffs play an important role in the analysis; fixed fees provide an additional instrument for profit-sharing which, in the absence of RPM, avoids double-marginalization problems; with RPM, these fees allow manufacturers to extract all retail revenues and thus encourage them to maintain monopoly prices and profits. However, fixed fees are not essential for the argument and other types of contracts would generate a similar analysis. Consider for example royalties instead of franchise fees. In the absence of RPM, they eliminate double marginalization as well and, together with RPM, asking each retailer to pay back to the manufacturer a percentage of its total profit (almost half of it, say) still sustains an equilibrium with monopoly prices.

Proposition 3 extends the insights of Bernheim and Whinston (1985) to the case of "double common agency". Our analyses share two essential "ingredients" that derive from some form of potential competition in the downstream market: $(i)$ retailers accept any offer as long as their expected profit is non-negative; and ( $i i)$ manufacturers cannot exclude their competitors. This derives here from the manufacturers' ability to use alternative retailers when an offer has been rejected. Other situations sharing the same ingredients (i) and (ii) would yield the same outcome:

perfect Bertrand competition between stores. Then, in the asymmetric Stackelberg scenario, the leader anticipates that the follower will undercut its price for $B$ (that is, $p_{B 2} \leq p_{B 1}$ ) and the analysis is the same as for a standard symmetric Stackelberg duopoly between a leader producing $A$ and a follower producing $B$.

${ }^{32}$ Since $\pi^{\prime}\left(p^{M}\right)=D\left(p^{M}\right)+\left(p^{M}-c-\gamma\right) \partial_{1} D=-\left(p^{M}-c-\gamma\right)\left(\partial_{2} D+\partial_{3} D+\partial_{4} D\right)<0$ (with all derivatives of $D$ evaluated at $\left.\mathbf{p}^{M}\right)$, this assumption holds whenever $\pi(p)$ is single-peaked. This is clearly the case in our linear demand example. 
- There could be more than one alternative retailer, and these alternative retailers might also carry both brands; in the same vein, the manufacturers could choose which retailer to contact first. Thus for example, the analysis would carry over when in each location there exists a competitive supply of potential retailers, to which the manufacturers propose contracts in turn, until an offer is accepted.

- Another possibility would be to extend the framework of Bernheim and Whinston (1985) to the case of multiple retail locations: we could for example allow manufacturers to make simultaneous (but withdrawable) offers to several retailers before choosing, in each location, (at most) one retailer among those that have accepted an offer. ${ }^{33}$

- Instead of using alternative retailers, a manufacturer could also sell directly to consumers. While establishing its own retail outlet might involve some significant set-up costs, our analysis would carry over as long as those set-up costs do not exceed the additional profit that they would generate, and as long as the marginal cost of direct distribution does not significantly exceed that of established retailers. This alternative might be particularly plausible in sectors where internet sales constitute a good substitute for in-store sales.

The admittedly ad-hoc but simplifying "market break-down" of the previous section is thus not crucial and there exists a wide range of situations for which monopoly prices (through the adoption of common retailers and RPM) constitute a likely outcome. They are indeed many markets with no retail bottlenecks, such as the car retailing sector for instance.

Note finally that, while the equilibrium multiplicity issue still arises here, it is however somewhat less acute than before: some of the previously-described equilibria involve low industry profits and would therefore be destabilized by a manufacturer's attempt to convince established retailers to carry only its own brand - thereby placing this manufacturer in the position of a (admittedly constrained) Stackelberg leader. In addition, the introduction of (arbitrarily small) retail efforts would again single out the equilibrium where retailers are residual claimants - and retail prices are at the monopoly level.

\section{Retail market power}

We now turn to situations where manufacturers cannot bypass established retailers. The existence of retail bottlenecks raises two issues. First, a manufacturer can now try to

\footnotetext{
${ }^{33}$ In a previous version of this paper (Rey and Vergé, 2004b), we obtained indeed a similar result using a framework more directly inspired by Bernheim and Whinston's original analysis of common agency.
} 
eliminate its rival, by inducing retailers to carry exclusively its own brand. While this might induce more competitive outcomes, we show that it can also prevent the brands from being offered at both stores - even though there is demand for each brand at each store. Second, retailers now have some market power and manufacturers must therefore share the profits with them. As a result, while RPM may again allow manufacturers to maintain monopoly prices, they may favor an equilibrium with lower retail prices in order to reduce retail rents - that is, they may prefer more competitive prices, and having a bigger share of a smaller pie.

Assuming that only the two established retailers (1 and 2) can reach consumers, we simply remove the part $(1-B)$ of our game $G$, i.e., once retailers have decided which contracts to accept, the game directly proceeds to stage 2 (downstream competition). In a double common agency situation, manufacturers must now ensure that retailers get at least as much as they could obtain by selling exclusively the rival brand; as we will see, this implies that manufacturers must leave a rent to retailers - that is, they cannot extract all the industry profits, even if they can make take-it-or-leave-it offers. ${ }^{34}$

The existence of these rents - and the fact that they must be evaluated for asymmetric structures too - somewhat complicates the analysis. We could provide a partial characterization of double common agency equilibria for general demand functions, but it is difficult to assess the existence of these equilibria and thus to evaluate the impact of RPM on prices and profits. In order to shed some light on these issues, we therefore restrict attention in this section to a linear model where costs are normalized to zero,

$$
c=\gamma=0
$$

and demand is given by: ${ }^{35}$

$$
D_{i j}(\mathbf{p})=1-p_{i j}+\alpha p_{h j}+\beta p_{i k}+\alpha \beta p_{h k},
$$

with $\alpha, \beta \geq 0$. The parameter $\alpha$ measures the degree of interbrand substitutability; the demands for brands $A$ and $B$ are independent when $\alpha=0$ and the brands become closer substitutes as $\alpha$ increases. Similarly, $\beta$ measures the degree of intrabrand substitutability. ${ }^{36}$ To ensure that demand decreases when all prices increase, we suppose

\footnotetext{
${ }^{34}$ They may be able to reduce retailers' rents by making both exclusive and non-exclusive offers; we rule out this possibility, however, in order to better assess the impact of retail market power.

${ }^{35}$ The expression of the demand is valid as long as all four products are effectively sold. When product $i j$ is not sold (e.g., when the above demand would be negative or when retailer $j$ refuses to carry brand $i$ ), the demand for the other products must be evaluated by replacing the price of that product with a virtual price $p_{i j}^{v}$, computed by equating $D_{i j}$ to zero (i.e., $p_{i j}^{v}=1+\alpha p_{h j}+\beta p_{i k}+\alpha \beta p_{h k}$ ).

${ }^{36}$ For the sake of exposition, we moreover assume that the parameter that measures the effect of an increase in one price on the demand for the rival brand at the rival store is simply the product of the intrabrand and interbrand parameters. This assumption is not critical, however. We have checked that a similar analysis applies when that parameter is instead set equal to 0 .
} 
$\alpha+\beta+\alpha \beta<1$.

\subsection{Two-part tariffs}

Starting with the case where RPM is not allowed, we first show that retailers' market power gives them positive rents whenever they carry both brands.

Given a vector of wholesale prices $\mathbf{w}=\left(w_{A 1}, w_{B 1}, w_{A 2}, w_{B 2}\right)$ (with the convention $w_{i j}=\emptyset$ if retailer $j$ does not carry brand $i$ ), at the last stage retail competition leads to a vector of equilibrium prices $\mathbf{p}^{r}(\mathbf{w})=\left(p_{i j}^{r}(\mathbf{w})\right)_{i ; j}$ (with $p_{i j}^{r}=p_{i j}^{v}$ if $w_{i j}=\emptyset$ - see footnote $35)$ and quantities $D_{i j}^{r}(\mathbf{w})=D\left(p_{i j}^{r}, p_{h j}^{r}, p_{i k}^{r}, p_{h k}^{r}\right)$. A retailer - retailer 1 , say - accepts to carry both brands if, by doing so, it earns profits that are not only non-negative, but also higher than what it could obtain by carrying a single brand. Therefore in any equilibrium where both retailers carry both brands, the contract between $A$ and 1 , say, must satisfy:

$$
\sum_{i=A, B}\left(p_{i 1}^{r}-w_{i 1}\right) D_{i 1}^{r}-F_{i 1} \geq \max \left\{0,\left(\hat{p}_{B 1}^{A 1}-w_{B 1}\right) \hat{D}_{B 1}^{A 1}-F_{B 1},\left(\hat{p}_{A 1}^{B 1}-w_{A 1}\right) \hat{D}_{A 1}^{B 1}-F_{A 1}\right\}
$$

where $\hat{p}_{i 1}^{h 1}$ and $\hat{D}_{i 1}^{h 1}$ (with $i \neq h \in\{A, B\}$ ) denote product $i 1$ 's price and quantity (that result from retail competition) when retailer 1 carries only brand $i .^{37}$

Removing brand $h$ from the store eliminates one of the available "products", and thus increases the demand for the remaining products. This gives retailer 1 an incentive to raise $p_{i 1}$, and the nature of the retail price equilibrium (strategic complementarity of prices, stability of the equilibrium) then implies that, in the new equilibrium, all retail prices are higher. Moreover, in the new equilibrium, retailer 1 makes more profit on brand $i$, both because of the report from brand $h$ and of the increase in the rival's prices. Therefore, $\left(\hat{p}_{i 1}^{h 1}-w_{i 1}\right) \hat{D}_{i 1}^{h 1}>\left(p_{i 1}^{r}-w_{i 1}\right) D_{i 1}^{r}$. Retailer 1 can therefore guarantee itself a positive profit. If retailer 1's profit was equal to 0 , then $\left(p_{i 1}^{r}-w_{i 1}\right) D_{i 1}^{r} \geq F_{i 1}$, for at least one $i \in\{A, B\}$. But this would imply $\left(\hat{p}_{i 1}^{h 1}-w_{i 1}\right) \hat{D}_{i 1}^{h 1} \geq F_{i 1}$, contradicting the retailer's participation constraint. In a symmetric situation, the retailers' relevant participation constraint is thus:

$$
\pi^{r}(w, w ; w, w)-2 F \geq \pi^{r}(\emptyset, w ; w, w)-F \Longleftrightarrow F \leq \pi^{r}(w, w ; w, w)-\pi^{r}(\emptyset, w ; w, w)
$$

where $\pi^{r}\left(w_{A j}, w_{B j} ; w_{A k}, w_{B k}\right) \equiv \sum_{i=A, B}\left(p_{i j}^{r}-w_{i j}\right) D_{i j}^{r}$ denotes the retail profit (gross of the franchise fees) of retailer $j$ for any vector of wholesale prices (again with the convention that $w_{i j}=\emptyset$ if retailer $j$ does not carry brand $i$ ).

The analysis carried out in the absence of retail bottlenecks (sections 3 and 4 ) relies on the premise that retailers' participation constraints are binding in equilibrium. The

\footnotetext{
${ }^{37}$ These prices and quantities are $\hat{p}_{B 1}^{A 1}=p_{B 1}^{r}\left(\emptyset, w_{B 1}, w_{A 2}, w_{B 2}\right), \quad \hat{D}_{B 1}^{A 1}=D_{B 1}^{r}\left(\emptyset, w_{B 1}, w_{A 2}, w_{B 2}\right)$, $\hat{p}_{A 1}^{B 1}=p_{A 1}^{r}\left(w_{A 1}, \emptyset, w_{A 2}, w_{B 2}\right)$ and $\hat{D}_{A 1}^{B 1}=D_{A 1}^{r}\left(w_{A 1}, \emptyset, w_{A 2}, w_{B 2}\right)$.
} 
possible existence of multiple continuation equilibria for a given set of offers complicates the analysis. If, for instance, the following inequalities hold:

$$
\pi^{r}(w, w ; w, \emptyset)-\pi^{r}(\emptyset, w ; w, \emptyset)<F<\pi^{r}(w, w ; w, w)-\pi^{r}(\emptyset, w ; w, w)
$$

there exist continuation equilibria of two types: one where both retailers carry both brands (double common agency) and one where one retailer carries brand $A$ while its rival carries brand $B$ ("single-branding"). Such multiplicity may then be used to sustain contracting outcomes in which retailers obtain more than is necessary to meet their participation constraints, by punishing deviating manufacturers through a switch to alternative, worse, continuation equilibria. In the linear model adopted in this section, there exists however a threshold $\bar{\beta}(\alpha)>0$ that guarantees that the continuation equilibrium is unique, thereby ensuring that the retailers' participation constraints must be binding in any (symmetric) common agency equilibrium. But, then we have:

Proposition 4 For any $\alpha$, there exists a threshold $\bar{\beta}(\alpha)>0$, such that, without Resale Price Maintenance, there exists no symmetric equilibrium with double common agency for $\beta<\bar{\beta}(\alpha)$.

\section{Proof. See Appendix D.}

Even though there is a positive demand for each brand at each store, there thus often does not exist an equilibrium where both retailers sell both products. The intuition is the following: in equilibrium, each retailer must be indifferent between accepting or refusing to carry each particular brand (see figure 1). A deviating manufacturer (manufacturer $A$, say) can therefore easily break this indifference and convince one retailer to accept only its own offer, while ensuring that the second retailer continues to carry both brands. It can indeed slightly change its wholesale price to break the indifference between carrying both brands and carrying brand $A$ only (this comparison does not depend on the fixed fee set by manufacturer $A$ ), and slightly change its fixed fee to break the indifference between carrying both brands and carrying brand $B$ only. Since the deviation can be made arbitrarily small, it does not affect the best responses to the other decisions by the rival retailer, and this guarantees that, in any continuation equilibrium, manufacturer $B$ is partially excluded: a retailer then carries both brands while its rival only carries brand $A$. Such a deviation does (almost) not affect the payments received by manufacturer $A$ through the fixed fees, but it increases its sales since brand $B$ is not longer carried by one retailer. The deviation is therefore profitable whenever the wholesale margin is positive.

Suppose now that the wholesale margin is non-positive $(w \leq c)$. Increasing the wholesale price for brand $A$ (charging $v>w$ ) would induce retailers to prefer carrying both 
brands rather than brand $A$ alone, ${ }^{38}$ and setting the fixed fee slightly below $\pi^{r}(v, w ; v, w)-$ $\pi^{r}(\emptyset, w ; v, w)$ would induce retailers to prefer carrying both brands rather than brand $B$ only. Such a deviation therefore maintains double common agency and is profitable whenever:

$$
\left.\frac{\partial\left((v-c) D_{A j}^{r}(v, w, v, w)+\pi^{r}(v, w ; v, w)-\pi^{r}(\emptyset, w ; v, w)\right)}{\partial v}\right|_{v=w}>0
$$

a condition which holds for any $w \leq c$ and $\beta<\bar{\beta}(\alpha)$.

As a result, and in contrast with the standard single common agent case (i.e., when distributing their products through a single retailer), there does not always exist a "double common agency" equilibrium. The main difference is that the rent that manufacturer $i$ must leave to retailer $j$ now depends on the tariff offered to retailer $k$, which implies that, when deviating towards "de facto exclusive deals", a manufacturer can also affect the rent it has to leave to each retailer.

\subsection{Resale price maintenance}

When manufacturers impose retail prices, in any symmetric equilibrium where both retailers carry both brands, the contract $(w, p, F)$ must meet the following two constraints: $F \leq(p-w) D(p, p, p, p)$, otherwise retailers would obtain negative profits and a retailer would never accept both contracts; and:

$$
\begin{aligned}
& 2((p-w) D(p, p, p, p)-F) \geq(p-w) D(p, \emptyset, p, p)-F \\
\Leftrightarrow \quad & F \leq(p-w) D(p, p, p, p)-(p-w)(D(p, \emptyset, p, p)-D(p, p, p, p)),
\end{aligned}
$$

where $D\left(p_{i j}, \emptyset, p_{h j}, p_{h k}\right)$ denotes the demand for brand $i$ at retailer $j$ when this retailer carries only that brand. Since removing a product increases the demand for the remaining ones, $D(p, \emptyset, p, p)>D(p, p, p, p)$, and retailers thus earn again a positive rent when the retailer margin $(p-w)$ is positive. The next proposition shows that such equilibria do exist and describe some of their properties:

Proposition 5 With RPM, any symmetric double common agency equilibrium with positive retail rents must be such that:

- the equilibrium wholesale and retail prices, $w_{i j}=w^{*}$ and $p_{i j}=p^{*}$, are inversely related and such that:

$$
w^{*}=\frac{1-2(1-\alpha-\beta) p^{*}}{\alpha(1-\beta)}
$$

\footnotetext{
${ }^{38}$ This is true in our linear model and would hold for more general demands as long as $\pi^{r}(v, w ; v, w)-\pi^{r}(v, \emptyset ; v, w)$ increases with $v$.
} 


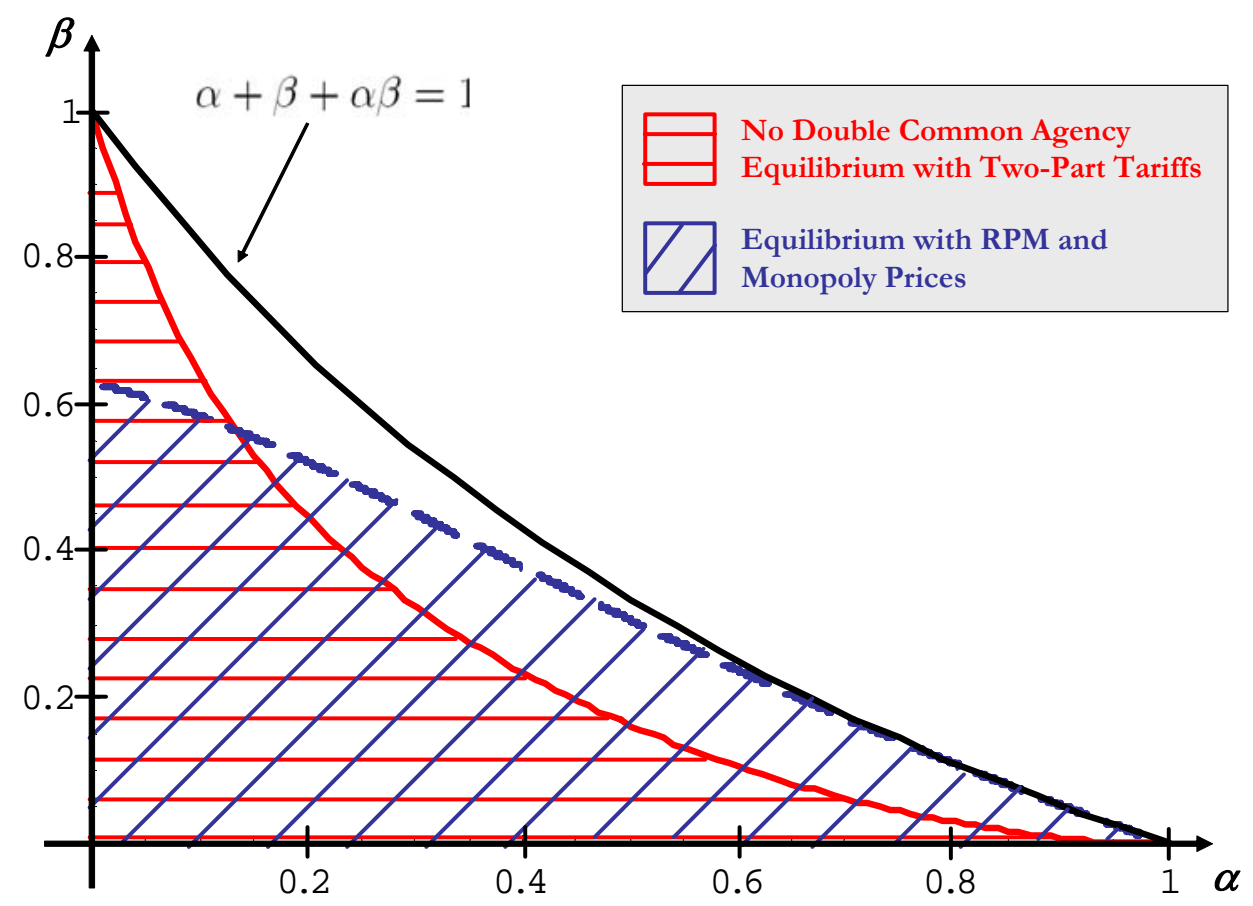

Figure 1: Existence of a double common agency equilibrium with monopoly prices

- retailers' profits are equal to $\left(p^{*}-w^{*}\right)\left(D\left(p^{*}, \emptyset, p^{*}, p^{*}\right)-D^{*}\right)$ and increase in $p^{*}$ as long as $p^{*} \leq p^{M}$

- manufacturers' profits are a decreasing function of $p^{*}$.

Conversely, for any $\alpha, \beta$ satisfying $\beta \leq \bar{\beta}^{R P M}(\alpha)$, where $\bar{\beta}^{R P M}(\alpha)>0$, there exists a symmetric double common agency equilibrium for any retail price in a range $I^{*}(\alpha, \beta)$, which includes the monopoly price $p^{M}$.

\section{Proof. See Appendix E.}

Note that proposition 5 only provides sufficient conditions for the existence of symmetric equilibria with double common agency. There may exist other equilibria, including other symmetric double common agency equilibria. Figure 1 represents the range of values for which the results of propositions 4 and 5 apply.

Despite the presence of retail rents, the equilibrium retail price is still inversely related to the equilibrium wholesale price. When manufacturer $h$ offers both retailers a wholesale price $w_{h}$ and imposes a retail price $p_{h}$, manufacturer $i$ 's best response, $\widetilde{p}\left(p_{h}, w_{h}\right)$, maximizes:

$$
\left(p_{i}-c-\gamma\right) D\left(p_{i}, p_{h}, p_{i}, p_{h}\right)+\left(p_{h}-w_{h}-\gamma\right)\left(D\left(p_{h}, p_{i}, p_{h}, p_{i}\right)-D\left(p_{h}, \emptyset, p_{h}, p_{i}\right)\right)
$$


Two effects are then at work. As in the absence of retail rents, manufacturer $i$ has an incentive to increase the sales of its own brands by being more aggressive, since it earns the full margin on these sales and only internalizes (through the fixed fees) the retail margin on the sales of its rival brand. Moreover, this incentive to free-ride on the rival brand is greater, the lower the retail margin on that brand. Therefore, in the absence of rents, an increase in the wholesale price $w_{h}$ makes manufacturer $i$ more aggressive.

However, a rent effect (corresponding to the negative term in the above expression) goes in the opposite direction. In order to reduce the rent left to retailer $j$, a manufacturer has an incentive to impose a low retail price on its rival, as this lowers the demand for retailer $j$. But, an increase in $w_{h}$ reduces, ceteris paribus, all retailers' rents and the manufacturer incentives to behave aggressively. This rent effect is however always dominated in the linear demand case; manufacturer $i$ 's reaction function, $\widetilde{p}\left(p_{h}, w_{h}\right)$, thus remains decreasing in $w_{h}$, as in the absence of rents, and the equilibrium retail $p^{*}$ is again inversely related to the equilibrium wholesale price $w^{*}$.

This rent effect however affects the wholesale price that is necessary to sustain monopoly retail prices. In the absence of rents, cost-based wholesale prices $\left(w_{h}=c\right)$ align each manufacturer's profit (up to a constant, equal to the sum of its rival's franchise fees) with the industry profit. This is no longer the case here due to the rent left to retailers. As a result, manufacturer $i$ 's best response to $p_{h}$ is lower than in the absence of rents, $\widetilde{p}\left(p_{h}, w_{h}\right)<\widehat{p}\left(p_{h}, w_{h}\right)$, which implies that, for cost-based wholesale prices $\left(w^{*}=c\right)$, the corresponding (symmetric) equilibrium retail price is below the monopoly level. In the linear demand case (with $c=\gamma=0$ ), we have indeed:

$$
p^{*}(0)=\frac{1}{2(1-\alpha-\beta)}<p^{M} .
$$

However, there exists some $w^{M}<0$ such that $p^{*}\left(w^{M}\right)=p^{M}$ : manufacturers can still sustain monopoly prices, but to do so they must set wholesale prices below their marginal cost of production.

Subsidizing wholesale prices increases retail rents, however. In equilibrium, this rent (per retailer and per brand) is equal to: ${ }^{39}$

$$
\pi_{R}^{*}=\left(p^{*}-w^{*}\right)\left[D\left(p^{*}, \emptyset, p^{*}, p^{*}\right)-D\left(p^{*}, p^{*}, p^{*}, p^{*}\right)\right]=\alpha\left(p^{*}-w^{*}\right) D^{*}
$$

Therefore,

$$
\frac{1}{\alpha} \frac{d \pi_{R}^{*}}{d p^{*}}=\frac{d\left(p^{*}-w^{*}\right)}{d p^{*}} D^{*}+\left(p^{*}-w^{*}\right) \frac{d D^{*}}{d p^{*}}
$$

Given the inverse relationship between $p^{*}$ and $w^{*}$, the mark-up $\left(p^{*}-w^{*}\right)$ increases with $p^{*}$ and this effect dominates when $p^{*}$ is small, since then $\left(p^{*}-w^{*}\right)$ is small and $D^{*}$ is large.

\footnotetext{
${ }^{39}$ In the linear case, $D\left(p^{*}, \emptyset, p^{*}, p^{*}\right)=(1+\alpha) D\left(p^{*}, p^{*}, p^{*}, p^{*}\right)$.
} 
Manufacturers' profits (per retailer) are of the form $\pi_{P}^{*}=p^{*} D^{*}-\pi_{R}^{*}$. Hence, manufacturers face a trade-off between increasing industry profits (by raising retail prices to the monopoly level) and reducing retail rents (by maintaining low retail prices). Proposition 5 shows that in this linear model, the rent effect dominates; therefore:

Corollary 1 Among the equilibria with double common agency described in proposition 5, manufacturers prefer the equilibrium with the lowest retail price, whereas retailers prefer the equilibrium with the highest retail price, which exceeds the monopoly level.

\section{Policy discussion and empirical validation}

Two recent empirical studies support our analysis. Biscourp, Boutin and Vergé (2008) [hereafter BBV] focus on the effects of the 1996 Galland Act, a French law clarifying the relevant price benchmarks for no below-cost pricing regulations. It has often been argued that this reform provided the manufacturers with an opportunity to abuse the regulations and de facto impose price floors. ${ }^{40}$ To test this possibility, BBV show that the positive correlation between retail prices and concentration across local markets observed before the Galland Act no longer existed after its enactment, thus supporting the view that RPM was indeed used to eliminate intrabrand competition in the latter period. To perform this test, BBV use prices collected monthly in almost 2000 retail stores for more than 190 product categories during the period 1994-1999 and construct local concentration indices (HHI indices based on sales areas) in each local market. They find that prices in monopolized markets were $15 \%$ higher than in competitive markets in 1994, and that this correlation was no longer significant in 1999. The use of such price floor mechanisms has been held responsible for (part of) the important price increases that have taken place in the last decade, especially for national brands in supermarket chains, ${ }^{41}$ which is in line with our analysis.

Bonnet and Dubois (2007 and 2008) test more directly our analysis (extended to account for 7 retailers (covering more than $70 \%$ of the retail market-, 3 manufacturers covering more than $70 \%$ of these retailers' sales, as well as multiple brands per manufacturer and private labels) using micro-level data (home-scan panel data of about 11000 French households) about the French market of bottled water during the 1998-2000 period. They build on Berto Villas-Boas (2007), who extends the empirical approach developed

\footnotetext{
${ }^{40} \mathrm{See}$, for example, the decisions of the Conseil de la Concurrence in Toys (07-D-50, December 2007), BVHE (05-D-70, December 2005) and Calculators (03-D-45, September 2003), or Commission Canivet (2005).

${ }^{41}$ Real food prices decreased by $8 \%$ between 1990 and 1997, but increased by 3\% between 1997 and 2001; no such change was observed in neighboring countries.
} 
by Berry, Levinsohn and Pakes (1995) to multiple stages of competition (upstream competition among manufacturers and downstream competition among retailers). In a first step, they use a random coefficient logit model to estimate the demand for the different brands of bottled water. They then compare alternative models of vertical and horizontal relationships between firms, using pairwise non-nested tests. ${ }^{42}$ Bonnet and Dubois (2007) compare 11 models, one with linear tariffs, one with a (horizontally and vertically) integrated monopoly and 9 with two-part tariffs (with and without RPM). Among the 9 models with two-part tariffs, 5 assume exogenous retail rents (as in our section 4) and 4 consider endogenous retail rents (as in our section 5). Although their tests are not nested, they find that one model outperforms the others, and that model involves exogenous rents, two-part tariffs and RPM, as in our section $4 .^{43}$

Bonnet and Dubois (2008) compare 12 different models (all with exogenous rents, as in our section 4) with linear or two-part wholesale tariffs, with or without RPM, with or without collusion on the upstream and/or the downstream market. They find that the same model as above outperforms again all the others. In that model, the retail margins are moreover squeezed $(p=w+\gamma)$. While the retail price is then lower than the monopoly level, they show that it is still $7.4 \%$ higher than the price that would prevail in the absence of RPM.

These recent empirical studies thus support our analysis, according to which RPM can (partially or fully) eliminate interbrand as intrabrand competition when rival manufacturers distribute their goods through the same competing retailers ("interlocking relationships"). As in the case of a single common agent, distributing their products through the same retailers allow the manufacturers to eliminate, or at least soften, interbrand competition. However, when dealing with several (common) retailers, intrabrand competition dissipates profits and prevents manufacturers from maintaining monopoly prices. In this context, RPM can restore monopoly prices and profits. In other words, RPM eliminates competition between retailers, while "common agency" eliminates competition between manufacturers. Since the mechanism identified by our analysis cannot be replicated through other vertical restraints (such as exclusive dealing or exclusive territories), this paper offers one argument supporting the authorities' rather negative attitude towards price restrictions.

Our analysis thus suggests a cautious attitude towards price restrictions in situations where rival manufacturers rely on the same competing retailers even in the absence of retail bottlenecks. It also supports the concerns of the French Conseil de la Concurrence when,

\footnotetext{
${ }^{42}$ The tests rely on the comparison between the estimated cost parameters and exogenously observed cost shifters.

${ }^{43}$ Berto Villas-Boas (2007) studies the distribution of yoghurts by supermarkets in California and also finds that non-linear prices are widely used. However, she does not test for the presence of RPM.
} 
as mentioned in the introduction, it condemned (in three separate cases) brown goods, perfume and toy manufacturers for engaging, through RPM, into "vertical collusion" with leading multi-brand retailers. 


\section{References}

[1] Allain, Marie-Laure and Claire Chambolle (2007), "Forbidding Resale at a Loss: A Strategic Inflationary Mechanism", mimeo.

[2] Amir, Rabah and Isabel Grilo (1994), "Stackelberg versus Cournot/Bertrand Equilibrium", Universite Catholique de Louvain CORE Discussion Paper 9424.

[3] Bernheim, Douglas and Michael Whinston (1985), "Common Agency as a Device for Facilitating Collusion", Rand Journal of Economics, 16(2), 269-281.

[4] Bernheim, Douglas and Michael Whinston (1998), "Exclusive Dealing", Journal of Political Economy, 106, 64-103.

[5] Berry, Steven, James Levinsohn and Ariel Pakes (1995), "Automobile Prices in Market Equilibrium", Econometrica, 63(4), 841-890.

[6] Berto Villas-Boas, Sofia (2007), "Vertical Relationships Between Manufacturers and Retailers: Inference With Limited Data", Review of Economic Studies, 74(2), 625652 .

[7] Biscourp, Pierre, Xavier Boutin and Thibaud Vergé (2008), "The Effects of Retail Regulations on Prices: Evidence from the Loi Galland", INSEE-DESE Discussion Paper G2008/02.

[8] Bonanno, Giacomo and John Vickers (1988), "Vertical Separation", Journal of Industrial Economics, 36, 257-265.

[9] Bonnet, Céline and Pierre Dubois (2007), "Non Linear Contracting and Endogenous Buyer Power between Manufacturers and Retailers: Identification and Estimation on Differentiated Products", mimeo.

[10] Bonnet, Céline and Pierre Dubois (2008), "Inference on Vertical Contracts between Manufacturers and Retailers Allowing for Non Linear Pricing and Resale Price Maintenance", mimeo.

[11] Caballero-Sanz, Francesco and Patrick Rey (1996), "The Policy Implications of the Economic Analysis of Vertical Restraints", Economic Papers $n^{\circ} 119$, European Commission.

[12] Caillaud, Bernard and Patrick Rey (1987). "A Note on Vertical Restraints with the Provision of Distribution Services." Working Paper INSEE and MIT. 
[13] Caillaud, Bernard and Patrick Rey (1995), "Strategic Aspects of Vertical Delegation", European Economic Review, 39, 421-431.

[14] Chen, Yongmin (1999), "Oligopoly Price Discrimination and Resale Price Maintenance", Rand Journal of Economics, 30(3), 441-455.

[15] Comanor, William (1985), "Vertical Price Fixing and Market Restrictions and the New Antitrust Policy", Harvard Law Review, 98, 983-1002.

[16] Comanor, William and Patrick Rey (1997), "Competition Policy towards Vertical Restraints in the US and Europe", Empirica, 24(1-2), 37-52.

[17] Commission Canivet (2005), Restaurer la concurrence par les prix: Les produits de grande consommation et les relations entre industrie et commerce, La Documentation Française.

[18] Deneckere, Raymond, Howard P. Marvel and James Peck (1996), "Demand Uncertainty, Inventories, and Resale Price Maintenance", Quarterly Journal of Economics, 111, 885-913.

[19] Deneckere, Raymond, Howard P. Marvel and James Peck (1997), "Demand Uncertainty and Price Maintenance: Markdowns as Destructive Competition", American Economic Review, 87, 619-641.

[20] Dobson, Paul and Michael Waterson (2007), "The Competition Effects of Industrywide Vertical Price Fixing in Bilateral Oligopoly", International Journal of Industrial Organization, 25(5), 935-962.

[21] European Commission (1996), Green Paper on Vertical Restraints.

[22] Gal-Or, Esther (1985), "First Mover and Second Mover Advantages", International Economic Review, 26(3), 649-653.

[23] Gal-Or, Esther (1991). "Duopolistic Vertical Restraints." European Economic Review, 35, 1237-1253.

[24] Hart, Oliver and Jean Tirole (1990), "Vertical Integration and Market Foreclosure", Brookings Papers on Economic Activity: Microeconomics, 205-276.

[25] Jullien, Bruno and Patrick Rey (2007), "Resale Price Maintenance and Collusion", Rand Journal of Economics, 38(4), 983-1001.

[26] Marvel, Howard P. and Stephen McCafferty (1984), "Resale Price Maintenance and Quality Certification", Rand Journal of Economics, 15(3), 346-359. 
[27] Mathewson, Frank and Ralph Winter (1998), "The Law and Economics of Resale Price Maintenance", Review of Industrial Organization, 13, 57-84.

[28] McAfee, R. Preston and Marius Schwartz (1994), "Opportunism in Multilateral Vertical Contracting: Nondiscrimination, Exclusivity and Uniformity", American Economic Review 84(1), 210-230.

[29] Motta, Massimo (2004), Competition Policy: Theory and Practice, MIT Press.

[30] O'Brien, Daniel and Greg Shaffer (1997), "Non-Linear Supply Contracts, Exclusive Dealing, and Equilibrium Market Foreclosure", Journal of Economics and Management Strategy, 6, 755-785.

[31] OECD (1994), Competition Policy and Vertical Restraints:Franchising Agreements, Paris.

[32] Rey, Patrick and Joseph Stiglitz (1988), "Vertical Restraints and Producers Competition", European Economic Review, 32, 561-568.

[33] Rey, Patrick and Joseph Stiglitz (1995), "The Role of Exclusive Territories in Producer's Competition", Rand Journal of Economics, 26, 431-451.

[34] Rey, Patrick and Jean Tirole (1986), "The Logic of Vertical Restraints", American Economic Review, 76, 921-939.

[35] Rey, Patrick and Jean Tirole (2007), "A Primer on Foreclosure", in Mark Armstrong and Rob Porter Eds., Handbook of Industrial Organization, Vol 3, North-Holland.

[36] Rey, Patrick and Thibaud Vergé (2004a), "Bilateral Control with Vertical Contracts", Rand Journal of Economics, 35(4), 728-746.

[37] Rey, Patrick and Thibaud Vergé (2004b), "Resale Price Maintenance and Horizontal Cartel", CMPO Working Paper 02/047.

[38] Rey, Patrick and Thibaud Vergé (2008), "The Economics of Vertical Restraints", in Paolo Buccirossi Ed., Handbook of Antitrust Economics, MIT Press.

[39] Schulz, Norbert (2007), "Does the Service Argument Justify Resale Price Maintenance?", Journal of Institutional and Theoretical Economics, 163(2), 236-255.

[40] Spence, Michael (1975), "Monopoly, Quality and Regulation", Bell Journal of Economics, 6, 417-429.

[41] Telser, Lester (1960), "Why Should Manufacturer Want Fair Trade," Journal of Law and Economics, 3, 86-105. 
[42] Wang, Hao (2004), "Resale price maintenance in an oligopoly with uncertain demand", International Journal of Industrial Organization, 22, 389-411. 


\section{A Proof of proposition 1}

We first show that equilibrium upstream margins are positive $\left(w^{e}>c\right)$. The conclusion then follows from the fact that manufacturers fail to account for (and thus "free-ride" on) their rivals' upstream margins. At a symmetric equilibrium of the form $\left(p_{i j}=p^{e}, w_{i j}=w^{e}\right)$, manufacturer $i$ must find it optimal to choose $w_{i 1}=w_{i 2}=w^{e}$ when its rival adopts $w_{h 1}=w_{h 2}=w^{e} ; w=w^{e}$ must therefore maximize:

$$
2\left[\left(\widetilde{p}\left(w, w^{e}\right)-c-\gamma\right) \widetilde{D}\left(w, w^{e}\right)+\left(\widetilde{p}\left(w^{e}, w\right)-w^{e}-\gamma\right) \widetilde{D}\left(w^{e}, w\right)\right] .
$$

The first-order condition yields (with $D$ evaluated at $p^{e}$ and the derivatives of $\widetilde{D}$ and $\widetilde{p}$ evaluated at $\left.\left(w^{e}, w^{e}\right)\right):\left(\partial_{1} \widetilde{p}+\partial_{2} \widetilde{p}\right) D+\left(p^{e}-c-\gamma\right) \partial_{1} \widetilde{D}+\left(p^{e}-w^{e}-\gamma\right) \partial_{2} \widetilde{D}=0$, implying:

$$
\left(\partial_{1} \widetilde{p}+\partial_{2} \widetilde{p}\right) D+\left(\partial_{1} \widetilde{D}+\partial_{2} \widetilde{D}\right)\left(p^{e}-w^{e}-\gamma\right)=-\left(w^{e}-c\right) \partial_{1} \widetilde{D}
$$

Note that $\partial_{1} \widetilde{D}=\lambda_{M} \partial_{1} \widetilde{p}+\hat{\lambda}_{M} \partial_{2} \widetilde{p}$ and $\partial_{2} \widetilde{D}=\lambda_{M} \partial_{2} \widetilde{p}+\hat{\lambda}_{M} \partial_{1} \widetilde{p}$, where $\lambda_{M} \equiv \partial_{1} D+\partial_{3} D$ represents the marginal impact on the demand for "product" ij of a uniform increase in the retail prices for brand $i$, while $\hat{\lambda}_{M} \equiv \partial_{2} D+\partial_{4} D$ represents instead the impact of the rival manufacturer's retail prices. Therefore, (5) can be rewritten as:

$$
\left(\partial_{1} \widetilde{p}+\partial_{2} \widetilde{p}\right)\left[D+\lambda\left(p^{e}-w^{e}-\gamma\right)\right]=-\left(w^{e}-c\right) \partial_{1} \widetilde{D}
$$

where $\lambda \equiv \lambda_{M}+\hat{\lambda}_{M}$ represents the impact on demand of a uniform increase in all retail prices and is thus negative. But a symmetric retail equilibrium is characterized by the first-order condition:

$$
D=-\lambda_{R}\left(p^{e}-w^{e}-\gamma\right),
$$

where $\lambda_{R} \equiv \partial_{1} D+\partial_{2} D$ represents the impact on the demand for "product" $i j$ of a uniform increase in retailer $j$ 's prices. Combining (6) and (7) yields:

$$
\left(\partial_{1} \widetilde{p}+\partial_{2} \widetilde{p}\right) \hat{\lambda}_{R}\left(p^{e}-w^{e}-\gamma\right)=-\left(w^{e}-c\right) \partial_{1} \widetilde{D}
$$

where $\hat{\lambda}_{R} \equiv \partial_{3} D+\partial_{4} D=\lambda-\lambda_{R}$ represents the marginal impact on demand of a simultaneous increase in the rival retailer's prices and is thus positive. Note that $\lambda_{R}<0$ (since $\lambda<0<\hat{\lambda}_{R}$ ), and thus (7) implies $p^{e} \geq w^{e}+\gamma$. But then, since $\partial_{1} \widetilde{p}+\partial_{2} \widetilde{p}>0$ and $\partial_{1} \widetilde{D}<0$ from Assumption 1, (8) implies $w^{e}>c$.

The first-order condition (5) can now be rewritten as:

$$
\left(\partial_{1} \widetilde{p}+\partial_{2} \widetilde{p}\right) D+\left(\partial_{1} \widetilde{D}+\partial_{2} \widetilde{D}\right)\left(p^{e}-c-\gamma\right)=\left(w^{e}-c\right) \partial_{2} \widetilde{D}
$$

Given that $\partial_{1} \widetilde{D}+\partial_{2} \widetilde{D}=\lambda\left(\partial_{1} \widetilde{p}+\partial_{2} \widetilde{p}\right)$ and $\partial_{1} \widetilde{p}+\partial_{2} \widetilde{p}>0$, having $w^{e}>c$ implies that $D+\lambda\left(p^{e}-c-\gamma\right)>0$. This in turn implies that, starting from $p=p^{e}$, a uniform increase in all prices increases the monopoly profit. By assumption the monopoly profit is singlepeaked at $p^{M}$ and thus, $p^{e}<p^{M}$. 


\section{B Proof of proposition 2}

If manufacturer $h$ adopts $w_{h 1}=w_{h 2}=w^{*}$ and $p_{h 1}=p_{h 2}=p^{*}$, from Assumption 2, manufacturer $i$ 's revenue function $\Pi$ is single-peaked in $\left(p_{i 1}, p_{i 2}\right)$ and maximal for symmetric prices, $\hat{p}_{i 1}=\hat{p}_{i 2}=\hat{p}\left(p^{*}, w^{*}\right)$; the price $p=\hat{p}$ maximizes $\Pi\left(p, p^{*}, p, p^{*}, w^{*}, w^{*}\right)$ and thus solves:

$$
\max _{p} f\left(p, p^{*}, w^{*}\right) \equiv(p-c-\gamma) D\left(p, p^{*}, p, p^{*}\right)+\left(p^{*}-w^{*}-\gamma\right) D\left(p^{*}, p, p^{*}, p\right)
$$

Obviously, $p^{M}=\hat{p}\left(p^{M}, c\right)$; thus $\left(w^{*}=c, p^{*}=p^{M}\right)$ always constitutes an equilibrium. In addition, for any wholesale price $w^{*} \in W$ there exists a unique price $p^{*}$ satisfying $p^{*}=\hat{p}\left(p^{*}, w^{*}\right)$, characterized by the first-order equation:

$$
D+\lambda_{M}\left(p^{*}-c-\gamma\right)+\hat{\lambda}_{M}\left(p^{*}-w^{*}-\gamma\right)=0
$$

where, as before, $\lambda_{M} \equiv \partial_{1} D+\partial_{3} D$ and $\hat{\lambda}_{M} \equiv \partial_{2} D+\partial_{4} D$. To establish that $p^{*}$ decreases when $w^{*}$ increases, note that $\partial_{13}^{2} f=-\hat{\lambda}_{M}\left(p^{*}, \hat{p}, p^{*}, \hat{p}\right)<0$. Therefore, a standard revealed preference argument leads to $\partial_{2} \hat{p}<0$. From Assumption 2, $0<\partial_{1} \hat{p}<1$, implying that the unique fixed point of $p \rightarrow \hat{p}\left(p, w^{*}\right)$ decreases when $w^{*}$ increases.

\section{Proof of proposition 3}

The proof is constructive and based on the following candidate equilibrium path: both manufacturers offer the contract $C^{c}=\left(w^{c}=c, p^{c}=p^{M}, F^{c}=\left(p^{M}-c-\gamma\right) D\left(\mathbf{p}^{M}\right)\right)$ to the "established" retailers 1 and 2 and all four offers are accepted at stage $1-A$. Retailers thus make zero profits and manufacturers share the monopoly profit.

\section{No profitable deviation for the retailers}

Since rejecting both offers yields zero profit for a retailer, the only deviation to consider is when retailer $j$, say, rejects one, and only one, offer (say manufacturer $i$ 's offer). Since $w^{c}=$ $c$, manufacturer $i$ then always finds it profitable to deal with the alternative retailer $j_{i}$, and, under Assumption 4, sets a retail price satisfying $p^{* *}=\arg \max (p-c-\gamma) D\left(p, p^{M}, p^{M}, p^{M}\right)<p^{M}$. Retailer $j$ then sells a quantity of product $h-j$ lower than $D\left(\mathbf{p}^{M}\right)$ and thus achieves a negative profit.

\section{No profitable deviation for the manufacturers}

A deviation by manufacturer $i$ at stage $(1-A)$ may affect the set of contracts that are accepted at this stage. We therefore evaluate the profitability of such a deviation for all 
possible market structures. Remember that if all offers $C^{c}$ are accepted, manufacturer $i$ gets $\frac{\pi^{M}}{2}$. The deviations fall into three categories:

\section{Manufacturer $h$ 's offers have both been accepted}

We can easily rule out any such deviation since both retailers $j$ and $k$ would then have accepted to pay $F^{c}=\frac{\pi^{M}}{4}$ each to the manufacturer $h$. Since the industry profit cannot exceed $\pi^{M}$, and a retailer would never accept an offer that generates losses, manufacturer $i$ cannot obtain than $\pi^{M}-2 F^{c}=\frac{\pi^{M}}{2}$.

\section{Manufacturer $h$ 's offers have both been rejected}

At stage $(1-B)^{\prime}$, manufacturer $h$ thus deals with the alternative retailers $\left(1_{h}\right.$ and $\left.2_{h}\right)$ and chooses the prices, $p_{h 1}$ and $p_{h 2}$, that are its best replies to the prices $p_{i 1}$ and $p_{i 2}$ that have either been accepted by the retailer(s) at stage $(1-A)$, or that are set by manufacturer $i$ (dealing with retailers $1_{i}$ and $2_{i}$ ) at stage $(1-B)^{\prime}$. The prices $p_{h 1}$ and $p_{h 2}$ are therefore equal to the prices set by the follower of our first Stackelberg scenario when the leader sets prices $p_{i 1}$ and $p_{i 2}$. Given that manufacturer $i$ 's profit can only come from the sales of products $i-1$ and $i-2$ (through either the "established" or the "alternative" retailers), its profit cannot exceed that of the leader of this first Stackelberg scenario which, by Assumption 3, is lower than $\frac{\pi^{M}}{2}$.

\section{Only one of manufacturer $h$ 's offers has been accepted (say, by retailer $j$ )}

At stage $(1-B)^{\prime}$, manufacturer $h$ thus sells product $h k$ through the "alternative" retailer $k_{h}$. Since $w_{h j}=c$, it chooses the price $p_{h k}$ that maximizes the profit made on the sales of this product. This price is thus the follower's best response in our second Stackelberg scenario where the leader sets prices $p_{i 1}, p_{i 2}$ and $p_{h 1}=p^{M}$.

We now have two possibilities to consider depending on whether the deviation is such that retailer $j$ accepts manufacturer $i$ 's offer or not.

- Suppose first that the deviation induces retailer $j$ to accept manufacturer $i$ 's offer. In this case, manufacturer $i$ can recover, through the franchise $F_{i j}$, the retail profit made by retailer $j$ on products $i j$ and $h j$ minus the franchise $F^{C}=\frac{\pi^{M}}{4}$ to be paid to manufacturer $h$. Given that $w_{h j}=c$ and $p_{h j}=p^{M}$, manufacturer $i$ 's profit is thus equal to:

$$
\left(p_{i j}-c\right) D_{i j}(\mathbf{p})+\left(p_{i k}-c\right) D_{i k}(\mathbf{p})+\left(p^{M}-c\right) D_{h j}(\mathbf{p})-\frac{\pi^{M}}{4} .
$$

Since $p_{h k}$ "best-responds" to the other prices - and $p_{h j}$ is moreover required to be equal to $p^{M}$ - this profit cannot exceed that of the leader of the second Stackelberg scenario minus $\frac{\pi^{M}}{4}$, which under Assumption 3 is lower than $\frac{3 \pi^{M}}{4}-\frac{\pi^{M}}{4}=\frac{\pi^{M}}{2}$. 
- Suppose finally that the deviation is such that the offer $i j$ is rejected. For such a situation to arise at the end of stage $1-A$, the contracts must be such that retailer $j$ expects its retail profit (on product $h j$ ) to cover the franchise to be paid to manufacturer $h$. That is, the profit generated by product $h j,\left(p_{h j}-c\right) D_{h j}(\mathbf{p})$ must cover the fee $F_{h j}^{*}=\frac{\pi^{M}}{4}$. Therefore, manufacturer $i$ 's profit is at most equal to

$\left(p_{i j}-c\right) D_{i j}(\mathbf{p})+\left(p_{i k}-c\right) D_{i k}(\mathbf{p}) \leq\left(p_{i j}-c\right) D_{i j}(\mathbf{p})+\left(p_{i k}-c\right) D_{i k}(\mathbf{p})+\left(p^{M}-c\right) D_{h j}(\mathbf{p})-\frac{\pi^{M}}{4}$,

where, for the same reason as above, the right-hand side cannot exceed $\frac{\pi^{M}}{2}$.

\section{Proof of proposition 4}

We now focus here on parameter values $\alpha$ and $\beta$ for which:

$$
\pi^{r}(w, w ; w, w)-\pi^{r}(w, \emptyset ; w, w)<\pi^{r}(w, w ; \emptyset, w)-\pi^{r}(w, \emptyset ; \emptyset, w)
$$

i.e., the gain from accepting both offers rather $A$ 's offer only is larger when the rival retailer accepts $B$ 's offer only than when it accepts both offers. In the linear demand case, it can be shown that condition (9) does not depend on $w$, and simply rewrites as $\beta<\bar{\beta}(\alpha)$, where $\bar{\beta}(\alpha)>0$ is uniquely defined.

If in addition:

$$
F<\pi^{r}(w, w ; w, w)-\pi^{r}(w, \emptyset ; w, w)
$$

then it can be checked that (i) rejecting both offers is a strictly dominated strategy, and (ii) carrying both brands is retailer $j$ 's strictly preferred choice whenever its rival is active. Double common agency is thus the unique continuation equilibrium. Since (10) continues to hold when the manufacturer slightly increases its franchise fees, this move is profitable since it induces the same double common agency outcome but raises the manufacturer's revenue from fixed payments. Therefore, in any (symmetric) double common agency equilibrium, we must have

$$
F=\pi^{r}(w, w ; w, w)-\pi^{r}(w, \emptyset ; w, w)
$$

Conversely, when (9) and (11) hold, it can be checked that:

- Rejecting both offers is a strictly dominated strategy.

- When retailer $k$ carries one brand only, retailer $j$ strictly prefers to carry both brands.

- When retailer $k$ carries both brands, retailer $j$ is indifferent between carrying both brands or one only. 
Concentrate first on $w>0$ and consider a deviation where manufacturer $A$ offers both retailers the contract $(v, G)$, where $v=w-\varepsilon, G=\pi^{r}(v, \emptyset ; v, w)-\pi^{r}(\emptyset, w ; v, w)+F-\eta$, and $\varepsilon, \eta>0$. When $\varepsilon$ and $\eta$ tend to $0,(v, G)$ tends to $(w, F)$. Therefore, for $\varepsilon$ and $\eta$ small enough, rejecting both offers remains a dominated strategy and it is then a best reply for a retailer to accept both contracts whenever its rival retailer carries only one brand. Conversely, if the rival accepts both offers, the unique best response is to accept only manufacturer $A$ 's offer; indeed, it is better to accept only $A$ 's offer rather than only $B$ 's offer since $G$ is designed so that:

$$
\pi^{r}(v, \emptyset ; v, w)-G=\pi^{r}(\emptyset, w ; v, w)-F+\eta>\pi^{r}(\emptyset, w ; v, w)-F
$$

Similarly, it is better to accept only $A$ 's offer rather than both offers when:

$$
\begin{aligned}
& \pi^{r}(v, \emptyset ; v, w)-G>\pi^{r}(v, w ; v, w)-G-F \\
\Leftrightarrow \quad & \pi^{r}(w, w ; w, w)-\pi^{r}(w, \emptyset ; w, w)>\pi^{r}(v, w ; v, w)-\pi^{r}(v, \emptyset ; v, w),
\end{aligned}
$$

a condition which is always satisfied in the linear demand case whenever $v<w$. This deviation thus allows manufacturer $A$ to partially exclude its rival; by doing so, it increases its sales without (substantially) affecting the franchise fees it receives. The deviation is thus profitable as long as the wholesale margin is strictly positive $(w>0)$.

Suppose now that $w \leq 0$ and suppose that manufacturer $A$ deviates and offers both retailers the contract $(v, G)$, where $v=w+\varepsilon$ and:

$$
G=\pi^{r}(v, w ; v, w)-\pi^{r}(\emptyset, w ; v, w)-\eta
$$

where $\varepsilon, \eta>0$ but close to 0 . In the linear case, it is possible to check that both $\pi^{r}(v, w ; v, w)-\pi^{r}(v, \emptyset ; v, w)$ and $\pi^{r}(v, w ; v, w)-\pi^{r}(\emptyset, w ; v, w)$ increase with $v$; as a result, double common agency is the unique continuation equilibrium, and the deviation, which gives to manufacturer $A$ a per retailer profit equal to:

$$
\Pi_{A}^{d e v}(v ; w)=(v-c) D_{i j}^{r}(v, w, v, w)+\pi^{r}(v, w ; v, w)-\pi^{r}(\emptyset, w ; v, w)-\eta,
$$

is indeed profitable for $\varepsilon, \eta>0$ close enough to 0 , since:

$$
\left.\partial_{v}\left((v-c) D_{i j}^{r}(v, w, v, w)\right)\right|_{v=w}=D_{i j}^{r}+(w-c)\left(\partial_{1} D_{i j}^{r}+\partial_{3} D_{i j}^{r}\right)>0 .
$$

Therefore, no "double common agency equilibrium" exists when $\beta<\bar{\beta}(\alpha)$.

\section{E Proof of proposition 5}

We focus on the case where the retail margin is positive. It can then be checked that, whenever the participation constraint holds strictly, the continuation equilibrium is unique, which in turn implies that the constraint must be binding in equilibrium. 
Let us denote by $\Pi\left(p_{1}, p_{2} ; p, w\right)$ the following revenue function:

$$
\begin{aligned}
\Pi\left(p_{1}, p_{2} ; p, w\right)=\sum_{j \neq k=1,2} & \left(\left(p_{j}-c-\gamma\right) D\left(p_{j}, p, p_{k}, p\right)\right. \\
& \left.+(p-w-\gamma)\left(D\left(p, p_{j}, p, p_{k}\right)-D\left(p, \emptyset, p, p_{k}\right)\right)\right) .
\end{aligned}
$$

This function is strictly concave in $\left(p_{1}, p_{2}\right)$ and maximal for symmetric prices, $\widetilde{p}_{1}=\widetilde{p}_{2}=$ $\widetilde{p}(p, w)$. Moreover, for any $w$, the function $p \rightarrow \widetilde{p}(p, w)$ has a unique fixed point, given by:

$$
p=p^{*}(w) \equiv \frac{1-\alpha(1-\beta) w}{2(1-\alpha-\beta)} \quad \Leftrightarrow \quad w=w^{*}(p) \equiv \frac{1-2(1-\alpha-\beta) p}{\alpha(1-\beta)} .
$$

We now prove that, in any (symmetric) double common agency equilibrium with positive retail margins, we must have $p=p^{*}(w)$. Suppose that manufacturer $A$ deviates and offers both retailers the contract $(v, G ; r)$, where $r=p+\varepsilon$ (with $\varepsilon$ close to 0 ), and:

- The wholesale price $v$ is adjusted so that, when retailer $k$ accepts both offers, retailer $j$ strictly prefers to accept both offers rather than manufacturer $A$ 's offer only:

$$
(r-v-\gamma) D(r, p, r, p)+(p-w-\gamma) D(p, r, p, r)-F>(r-v-\gamma) D(r, \emptyset, r, p) .
$$

- The fixed fee $G$ is adjusted so that, when retailer $k$ accepts both offers, retailer $i$ strictly prefers to accept both offers rather than manufacturer $B$ 's offer only:

$$
(r-v-\gamma) D(r, p, r, p)-G+(p-w-\gamma) D(p, r, p, r)=(p-w-\gamma) D(p, \emptyset, p, r)+\eta,
$$

with $\eta>0$ close to 0 .

Since the deviation from $(w, F ; p)$ is small, it ensures that double common agency remains the unique continuation equilibrium. Manufacturer $A$ 's gain from deviating from the contract $(w, F ; p)$ is thus $\Pi(p+\varepsilon, p+\varepsilon ; p, w)-\Pi(p, p ; p, w)-2 \eta$. Since $\eta$ can be made as small as needed, this gain is positive whenever $p \neq \widetilde{p}(p, w) \Leftrightarrow p \neq p^{*}(w) .{ }^{44}$

We now look for sufficient conditions on $p^{*}$ to ensure that the contract $\left(w^{*}\left(p^{*}\right), p^{*}, F^{*}\left(p^{*}\right)\right)$, where:

$$
F^{*}(p) \equiv(1-\alpha)\left(p-w^{*}(p)\right) D(p, p, p, p)
$$

indeed supports an equilibrium under RPM. Given the previous discussion, it remains to check that there are no profitable deviations for the manufacturers. We only sketch the proof here; a more detailed proof is available upon request. We moreover restrict attention to outcomes satisfying $p^{*} \geq w^{*}$ and $q^{*}=D\left(\mathbf{p}^{*}\right) \geq 0$, which is equivalent to:

$$
p^{*} \in \hat{I} \equiv\left[\frac{1}{2-\alpha-2 \beta-\alpha \beta}, \frac{1}{1-\alpha-\beta-\alpha \beta}\right] .
$$

A deviation by a manufacturer can lead to 16 possible market structures. Symmetry however reduces this number to 10; it moreover can not be profitable to deviate in such a way that both retailers reject the offers, which leaves only 7 types of deviations to analyze.

\footnotetext{
${ }^{44}$ More specifically, if $p<\widetilde{p}(p, w)$ (resp.,$p>\widetilde{p}(p, w)$ ), the gain from deviating is positive whenever $\varepsilon>0$ (resp., $\varepsilon<0)$.
} 


\section{Structure 0: double common agency}

For double common agency to remain a (possibly not unique) continuation equilibrium, manufacturer $A$, say, needs to ensure that each retailer is indeed willing to accept both offers rather than manufacturer $B$ 's offer only, when its rival accepts both offers. The wholesale and retail prices offered (or induced) by $A$, which we denote by $\left(w_{1}, w_{2}\right)$ and $\left(p_{1}, p_{2}\right)$, must therefore satisfy: for any $j \neq k \in\{1,2\}$,

$$
\begin{aligned}
& \left(p_{j}-w_{j}\right) D\left(p_{j}, p^{*}, p_{k}, p^{*}\right)-F_{j} \\
+ & \left(p^{*}-w^{*}\right) D\left(p^{*}, p_{j}, p^{*}, p_{k}\right)-F^{*} \geq\left(p^{*}-w^{*}\right) D\left(p^{*}, \emptyset, p^{*}, p_{k}\right)-F^{*} .
\end{aligned}
$$

These necessary conditions impose an upper bound on manufacturer $A$ 's fees; ${ }^{45}$ its profit thus cannot exceed:

$\Pi\left(p_{1}, p_{2} ; p^{*}, w^{*}\right)=\sum_{j \neq k=1,2} p_{j} D\left(p_{j}, p^{*}, p_{k}, p^{*}\right)+\left(p^{*}-w^{*}\right)\left(D\left(p^{*}, p_{j}, p^{*}, p_{k}\right)-D\left(p^{*}, \emptyset, p^{*}, p_{k}\right)\right)$.

For linear demands, (12) ensures that this function is maximal for $p_{1}=p_{2}=p^{*}$, when it coincides with the equilibrium profit when $F^{*}$ satisfies (13). A deviation to "double common agency" is therefore not profitable.

\section{Structure 1: $(i j-i k-h j)$, contract $C_{h k}$ is rejected.}

To ensure that this structure constitutes a possible continuation equilibrium, the contracts $C_{A 1} \equiv\left(w_{1}, F_{1} ; p_{1}\right)$ and $C_{A 2} \equiv\left(w_{2}, F_{2} ; p_{2}\right)$ offered by manufacturer $A$ must satisfy the following necessary conditions:

$$
\begin{aligned}
& \left(p_{1}-w_{1}\right) D\left(p_{1}, p^{*}, p_{2}, \emptyset\right)-F_{1} \\
& +\left(p^{*}-w^{*}\right) D\left(p^{*}, p_{1}, \emptyset, p_{2}\right)-F^{*} \geq \max \left[0,\left(p^{*}-w^{*}\right) D\left(p^{*}, \emptyset, \emptyset, p_{2}\right)-F^{*}\right]
\end{aligned}
$$

and

$$
\left(p_{2}-w_{2}\right) D\left(p_{2}, \emptyset, p_{1}, p^{*}\right)-F_{2} \geq \max \left[0,\left(p^{*}-w^{*}\right) D\left(p^{*}, \emptyset, p^{*}, p_{1}\right)-F^{*}\right],
$$

which again determine an upper bound on manufacturer $A$ 's fees; its profit then cannot exceed:

$$
\begin{aligned}
\Pi^{1}\left(p_{1}, p_{2} ; p^{*}, w^{*}\right)= & p_{1} D\left(p_{1}, p^{*}, p_{2}, \emptyset\right)+p_{2} D\left(p_{2}, \emptyset, p_{1}, p^{*}\right)+\left(p^{*}-w^{*}\right) D\left(p^{*}, p_{1}, \emptyset, p_{2}\right)-F^{*} \\
& -\max \left[0,\left(p^{*}-w^{*}\right) D\left(p^{*}, \emptyset, \emptyset, p_{2}\right)-F^{*}\right] \\
& -\max \left[0,\left(p^{*}-w^{*}\right) D\left(p^{*}, \emptyset, p^{*}, p_{1}\right)-F^{*}\right]
\end{aligned}
$$

This type of deviation is therefore not profitable if:

$$
\max _{\left(p_{1}, p_{2}\right)} \Pi^{1}\left(p_{1}, p_{2} ; p^{*}, w^{*}\right) \leq \Pi\left(p^{*}, p^{*} ; p^{*}, w^{*}\right) .
$$

\footnotetext{
${ }^{45}$ Additional conditions must be met (for example a retailer should obtain non-negative profits). However, these constraints suffice here to rule out deviations.
} 
With linear demands, there exists indeed a non-trivial interval $I_{1}(\alpha, \beta) \subset \hat{I}$, such that condition (14) is satisfied for any $p^{*} \in I_{1}(\alpha, \beta)$.

\section{Remaining structures}

Repeating the analysis for each of the five remaining structures generates additional restrictions, $p^{*} \in I_{n}(\alpha, \beta)$, for any $n=2, \ldots, 6$. It can then be shown that there exists $\bar{\beta}^{R P M}(\alpha)$, displayed in figure 1 , such that $p^{M} \in I^{*}(\alpha, \beta) \equiv \bigcap_{n=1}^{6} I_{n}(\alpha, \beta)$ whenever $\beta \leq \bar{\beta}^{R P M}(\alpha)$. 